\title{
Collective Labour Supply: Heterogeneity and Nonparticipation
}

\author{
Richard Blundell; Pierre-Andre Chiappori† Thierry Magnac ${ }^{\ddagger}$ \\ and Costas Meghir ${ }^{\S}$
}

September 2006

\begin{abstract}
We present identification and estimation results for the "collective" model of labour supply in which there are discrete choices, censoring of hours and nonparticipation in employment. We derive the collective restrictions on labour supply functions and contrast them with restrictions implied by the usual "unitary" framework. Using the large changes in the wage structure between men and women in the UK over the last two decades we estimate a collective labor supply model for married couples without children. The implications of the unitary framework are rejected while those of the collective approach are not. The estimates of the sharing rule show that wages have a strong influence on bargaining power within couples.
\end{abstract}

${ }^{*}$ University College London, Department of Economics, Gower Street, London, WC1E 6BT and Institute for Fiscal Studies.

${ }^{\dagger}$ University of Chicago, Department of Economics, and Columbia University, Department of Economics. Email: pc2167@columbia.edu

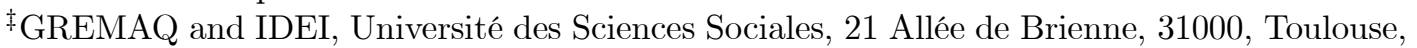
France.

$\S$ University College London, Department of Economics, Gower Street, London, WC1E 6BT and Institute for Fiscal Studies. 


\section{$1 \quad$ Introduction $^{1}$}

The standard unitary labour supply model is unable to explain a number of empirical facts. First, the assumption of income pooling, where the source of income does not matter for household behaviour is rejected (see for instance Thomas, 1990, Duflo, 2003, and the considerable literature on intrahousehold allocation). Second, the compensated substitution effects between male and female leisure, whenever compared are found not to be symmetric. Lastly, many recent studies have recognized that a lot of inequality may be hidden within households and the standard unitary model cannot handle this issue by construction. Both the empirical failings and intrahousehold inequality concerns lead directly to the question of how resources are allocated within households and how this is likely to change in response to changes in the environment.

When it comes to welfare assessment, policy evaluation and cost-benefit analysis, intrahousehold allocation is a crucial issue for several reasons. First, to the extent that policy makers are interested in individual well-being, analysis focusing on the inter-household level may be insufficient, if not misleading. One can easily find examples in which a policy, say, slightly ameliorates the well being of poorest households, but at the cost of a large increase in intrahousehold disparities - so that, in the end, poorest individuals are made significantly worse off. Disregarding

\footnotetext{
${ }^{1}$ Acknowledgements: We are grateful to three anonymous referees, James Dow, Francois Laisney, Jim Heckman, Tom MaCurdy, John Rust and Yoram Weiss for particularly helpful comments. We also thank participants at the AFSE, Carlos III, Chicago Econometrics seminar, Concordia University (Montreal), CREST, the IFS, Nantes University, NYU, SITE '98 - Stanford, and Paris-Jourdan, for their helpful comments. This research is part of the program of the ESRC Centre for the Micro-Economic Analysis of Fiscal Policy at IFS. The financial support of the Alliance program, ESRC, NSF and Commissariat general du Plan is gratefully acknowledged. Household data from the FES made available by the CSO through the ESRC Data Archive has been used by permission of the HMSO. Neither the CSO nor the ESRC Data Archive bear responsibility for the analysis or the interpretation of the data reported here. The usual disclaimer applies.
} 
these issues (or dismissing intrahousehold inequality issues as irrelevant) may thus lead to important policy errors.

A second and more subtle problem is directly linked to a crucial insight of bargaining theory, namely that changes in outside options may have a strong impact on behavior and welfare even for agents who are not directly affected by these options. For instance, the availability of unemployment benefits may affect the structure of the bargaining game between employers and employees, hence the situation of workers who do not actually receive these benefits. In the same vein, Haddad and Kanbur (1992), analyzing the welfare impact of guaranteed employment programs in India, stress that these programs, by generating credible outside options for women, may have a huge impact on intrahousehold allocation and decision process. They argue that standard cost-benefit analysis, which exclusively concentrates on the gains received by agents who actually participate in the program, may thus miss its major benefit, leading to a biased evaluation of its consequences. A third example, which lies at the core of the present paper, relates to the impact on wage increases on household behavior. In the standard, 'unitary' model, wages matter insofar as they affect the household's budget constraint; when a household member is not working, changes in his/her 'potential' wage cannot matter. Bargaining theory, on the other hand, suggest the opposite conclusion: if potential wages affect bargaining positions (say, because a member's threat point involves participation in the labor market), then any variation of the potential wage of an unemployed member will modify the behavior of (and the welfare allocation within) the household.

Clearly, these issues cannot be addressed within a unitary setting; a richer conceptual framework is needed, where individuals retain their identity within the household and where questions of individual welfare make sense. The 'collective' 
model of household behavior provides precisely such framework. In this paper we use and develop further the framework of Chiappori (1988) to estimate individual preferences and within household allocation rules based on observable labour supply decisions of the household. As suggested by the above discussion, we are primarily interested in participation decisions in general, and the role of wages of unemployed members in particular.

To empirically analyse these important wage effects in a convincing way we use the large changes in the wage structure between men and women over time in the UK to provide identification of the labour supply model without relying on arbitrary exclusion restrictions or on cross sectional variation in wages. In this empirical implementation we have to acknowledge certain features of observed family supply decisions. First, women's labour supply displays a wide range of hours of work and a substantive fraction do not work. Second, that male labour supply is discrete and does not fit the continuous choice paradigm which provides a reasonable approximation for female labour supply in couples. These features provide a key motivation for the approach we take to modelling collective labour supply in this paper.

Labour market participation and the Collective model An important motivation of our research is to disentangle the 'bargaining' aspects involved in participation decisions from the more standard income and substitution effects. A careful study of non participation is crucial in this respect, because the effect of changes in the potential wage of a non participating member provides key insights on the bargaining process.

When analyzing labor supply decisions of couples, the econometrician can allocate households into four different regimes, defined by the interaction of participation decisions of both spouses. Empirically, the information of interest is 
summarized by two 'participation frontiers' between regimes of participation for both members, as functions of any relevant covariates. Moreover, conditional on participation, labor supply functions provide additional information. Clearly, the four regimes are not equally informative in terms of both testability and identification. For instance, not much in terms of additional identifying power should be expected when considering the sample of households where both spouses do not work, since there are no other pieces of information on behavior in this regime. At the other extreme, the regime in which both spouses work has already been studied in the theoretical literature, from both a unitary and a collective perspective (Chiappori, 1988, 1992). This is the case where one should expect the strongest identifying power for preferences and any other function of interest (such as sharing rules), provided that we can condition the empirical analysis on the participation decisions.

It is only recently that other work regimes have been investigated; and this paper was the first to propose such an analysis. ${ }^{2}$ Our study is based on survey data (UK FES) over a long time span - one of the few long term surveys that allows for an empirical analysis of this type. As noted above these data display two important features. First a large proportion of women do not work; when they do, however, the range of hours that they supply is large. We thus have to discuss the implications of the collective framework when a good is on the corner. Second, although non-participation rates for men are large and approaching those for women over time, when men do work, they nearly always work full time. In our data set practically no men are seen to work for less than 35 hours a week and very few are seen to work for less than 52 weeks. As we illustrate in the empirical section, modelling the small variation of hours above 35 hours a week or below 52

\footnotetext{
${ }^{2}$ For a related work, see Donni (2003).
} 
weeks a year does not seem to us to be the most important issue to focus on.

These characteristics of the data lead to the basic methodological choices of our paper. Namely, we assume that the husband's decision is discrete (work or not) and that only this dimension of labor supply choice affects preferences. The collective framework we present thus breaks new ground. First, identification cannot rely on both labour supplies being continuous. Second, female labour supply is shown to vary with male wages even when he is not working, although this relationship operates in a restrictive way that can be tested. Third, our extension of the collective approach to discrete choices relies on an original assumption of "double indifference" towards labour market participation; we explore the theoretical foundations and the empirical consequences of this formalization on the collective approach, and in particular on the way intrahousehold allocation of resources operates in the neighbourhood of the participation frontiers. Finally, our model is not nested in the collective model with continuous hours (Chiappori, 1988) and thus extends the generality of the collective approach.

Identification From an econometric point of view we recognise the importance of unobserved heterogeneity, which in itself creates further difficult identification questions. We cannot analyze identification in each regime of participation as in the original homogenous case of Chiappori (1988) as new selection and other endogeneity issues arise. We discuss estimation within the context of parametric preference structures (i.e. linear or log-linear) and we show in the working paper version that given the functional form assumptions and exclusion restrictions, the restrictions originating from the collective framework overidentify the model in a semi-parametric way. ${ }^{3}$ For simplicity, we use full parametric assumptions in the

\footnotetext{
${ }^{3}$ Working paper with proofs and detailed discussions of many of the issues is available at http://www.ifs.org.uk/workingpapers/wp0119.pdf
} 
empirical analysis.

The framework we develop allows identification of preferences without using information on preferences for singles; we allow all parameters of the utility function to depend on whether one is married or not. The surprising result, in this context, is that the collective framework implies restrictions on household labor supply, even when male labor supply is discrete. Modelling household formation and dissolution and identifying the way that marriage affects preferences is of course another issue of critical importance. It is beyond the scope of this paper, although we view the present contribution as a crucial step in this direction.

In this paper we select only couples without children because we do not allow for public goods or for household production in the theoretical model we consider. Individuals can care about each other's welfare, but not by the way in which this welfare is generated. These restrictions would be particularly stringent in the presence of children, where the decisions on how many resources should be devoted to them is of central importance and is reflected in day to day flows in consumption. A clear implication is that our results are only directly valid for this group of individuals. However, this is a valuable first step in our attempt to construct empirical models in the more complex context of the collective models.

Main findings In this paper we use UK survey data (FES) for the years 1978 to 2001. Exploiting the large changes in the wage structure in the UK over this period to provide identification in itself distinguishes us from many other papers. Our results show that the unitary model is rejected; however the collective model is not rejected. In the collective model, the estimated female labor supply wage (respectively income) elasticity at mean wages is 0.66 (resp. -0.73) and these results conform well with previous results where the analysis is conditioned on the male working. 
In addition, new and interesting patterns emerge. Of particular interest, given the motivations stated above, is the finding that female labor supply depends on male wage even when the husband is not working. Moreover, the direction of this relationship goes exactly as predicted by a bargaining interpretation of the collective model. A male wage increase when he is working expands the household's total income, which in general benefits both members $;^{4}$ through a standard income effect, female number of hours should be reduced, which is what we find. On the contrary, a male wage increase when he is idle has no impact on the household's budget constraint, but influences the intrahousehold distribution of power. Indeed, we find that such an increase augments her working time, which suggest a reallocation of household resources in his favor. This result confirms the basic insights described above.

Finally, the estimation of the sharing rule implies that bargaining power is strongly affected by wages. One pound increase in his earnings when he is working increases his consumption by about 0.81 of a pound, while he gets to keep 0.67 of an increase in unearned income. When he does not work all these effects get compressed by to $68 \%$ of their values implying a greater shift of marginal resources to the wife.

Literature There are relatively few empirical studies of family labor supply outside the unitary model. A number of more recent studies have used micro data to evaluate the pooling hypothesis or to recover collective preferences using exclusive goods, but these studies typically look at private consumption rather than labor supply. For example, Thomas (1990) finds evidence against the pooling hypothesis by carefully examining household data from Brazil. Browning et al. (1996) use Canadian household expenditure data to examine the pooling hypothesis and to

\footnotetext{
${ }^{4}$ See Chiappori and Donni (2005) for a precise analysis of this issue.
} 
recover the derivatives of the sharing rule. Clothing in this analysis is the exclusive good providing identification, rather than labor supply which is problematical for a sample of couples without children who both work full-time.

Recent empirical studies concerning family labor supply include Lundberg (1988), Apps and Rees (1996), Kapteyn and Kooreman (1992) and Fortin and Lacroix (1997). Each of these aim to provide a test of the unitary model and to recover some parameters of collective preferences. Lundberg attempts to see which types of households, distinguished by demographic composition, come close to satisfying the hypotheses implied by the unitary model. The other three studies take this a step further by directly specifying and estimating labor supply equations from a collective specification. Apps and Rees (1996) specify a model to account for household production. Kooreman and Kapteyn (1990) use data on preferred hours of work to separately identify individual from collective preferences and, consequently, to identify the utility weight. Fortin and Lacroix (1997) follow closely the Chiappori framework and allow the utility weight to be a function of individual wages and unearned incomes. They use a functional form that nests both the unitary and the collective model as particular cases, and find that the restrictions implied by the unitary setting are strongly rejected, while the collective ones are not. In a more recent paper, Chiappori, Fortin and Lacroix (2002) extend the collective model to allow for 'distribution factors', defined as any variable that is exogenous with respect to preferences but may influence the decision process. Using PSID data and choosing the sex ratio as a distribution factor, they find that the restrictions implied by the collective model are not rejected; furthermore, they identify the intra-household sharing rule as a function of wages, non labor income and the sex ratio. It is important to note that the latter works assume that both male and female labor supplies vary continuously. The case of discrete male 
labor supply, which raises particular difficulties, is a specific contribution of the current paper; however, Donni (2003) applies similar ideas to taxation. Of course, there are issues that we do not address; these include uncertainty, intertemporal considerations, taxation and others. Some work has been carried out by Mazzocco (2003a and b, 2004), Attanasio and Mazzocco (2001) and Donni (2003). More is left for future research in this important field, which can build on our framework. ${ }^{5}$

We set up the homogenous model in Section 2 and discuss its identification, the collective restrictions and the corresponding restrictions in the unitary model. In Section 3, we specify the empirical model, report estimates and tests of unitary and collective restrictions. We present estimates of the sharing rule and labour supply functions when he works or not. In our final section we discuss how the model can be generalized to take into account of household production and public goods. We draw on work we have been developing to discuss some new identification results as well as data requirements for this more general problem.

\section{Theoretical Framework}

We now present the collective model for male and female labour supply, with discrete male labour supply. ${ }^{6}$ We then show how, given wages, other income and possible other exogenous variables, we can recover individual preferences and the sharing rule, from observations on labour supply of each individual. Our analysis is based on the assumption that within household allocations are efficient. This implies, among other things, that side-payments are possible. We view this as quite a natural assumption to make when modeling relationships of married individuals.

\footnotetext{
${ }^{5}$ Udry (1996) studies a related problem, namely the allocation of inputs to agricultural production in a developing country. He concludes that the decision process entails inefficiencies, in the sense that a different allocation between 'male' and 'female' crops could increase total production.

${ }^{6}$ The analysis assumes that unemployment is a labour supply decision.
} 
It turns out that, when preferences are egoistic or caring, this assumption is an identifying one. ${ }^{7}$ Preferences are defined over goods and non-market time. In the basic model, we assume that both these goods are private, and that there is no household production. The extension to account for household production is discussed in the concluding section of the paper where we also consider the case of public consumption. Although some of the assumptions underlying the basic model are restrictive, we think of it as best applying to the population of married couples with no children; children are likely to be the most important source of preference interdependence, which we choose to exclude for the moment.

The original Chiappori (1988) theorem relied on the idea that when allocations are efficient (as assumed) the marginal rates of substitution between members in a household are equalized. In our case, in which there is censoring and where one of the individuals faces discrete choice for one of the goods, the derivation of the implications of the collective setting has to follow a different logic. In what follows below we present the model and its assumptions formally and derive restrictions on labor supply functions. We finish the section by deriving similar restrictions of the unitary model.

\subsection{The General Collective Labor Supply Model}

\subsubsection{Preferences and decision process}

We consider a labor supply model within a two-member household; let $h^{i}$ and $C^{i}$ denote member i's labor supply (with $i=m, f$ and $0 \leq h^{i} \leq 1$ ) and consumption of a private Hicksian commodity $C$ (with $C^{f}+C^{m}=C$ ) respectively. The price of the consumption good is set to one. We assume preferences to be

\footnotetext{
${ }^{7}$ Browning and Chiappori (1998) and Chiappori and Ekeland (2002) show that efficiency alone (with general preferences) cannot provide testable restrictions upon behavior unless the number of commodities is at least 5; in addition, even with more than four commodities preferences are not identifiable.
} 
'egoistic' type; i.e., member i's utility can be written $U^{i}\left(1-h^{i}, C^{i}\right)$, where $U^{i}$ is continuously differentiable, strictly monotone and strongly quasi-concave. ${ }^{8}$ Also, let $w_{f}, w_{m}$ and $y$ denote wages and the household's non labor income respectively.

A common assumption in previous works on collective labor supply (Chiappori, 1988, 1992; Fortin and Lacroix, 1997; Chiappori, Fortin and Lacroix, 2002) was that both labor supplies could vary continuously in response to fluctuations in wages and non labor income. If $h^{m}$ and $h^{f}$ are twice differentiable functions of wages and non labor income, then generically, the observation of $h^{m}$ and $h^{f}$ allows to test the collective setting and to recover individual preferences and individual consumptions of the private good up to an additive constant (Chiappori, 1988). Empirically, however, the continuity assumption is difficult to maintain. As shown in the empirical section, while female labor supply varies in a fairly continuous manner, male labor supply is essentially dichotomous. A first purpose of this paper is precisely to show that the collective model implies restrictions in the case where one labor supply is constrained to take only two values. ${ }^{9}$ Hence we assume throughout the paper that member $f$ can freely choose her working hours, while member $m$ can only decide to participate (then $\left.h^{m}=1\right)$ or not $\left(h^{m}=0\right)$. Let $P$ denote the participation set, i.e., the set of wage-income bundles such that $m$ does participate. Similarly, $N$ denotes the non-participation set, and $L$ is the participation frontier between $P$ and $N$.

As the household is assumed to take Pareto-efficient decisions, there exists for any $\left(w_{f}, w_{m}, y\right)$, some $\bar{u}^{m}\left(w_{f}, w_{m}, y\right)$ such that $\left(h^{i}, C^{i}\right)$ is a solution to the program:

\footnotetext{
${ }^{8}$ The utility functions can be of the caring type: Each individual may care about the overall welfare of their partner, so long as they do not care about how it comes about.

${ }^{9}$ This set-up is not nested and does not nest the continuous model since choice sets are different. The analysis could easily be extended to any discrete labor supply function; for instance, the choice might be between non activity, part-time or full-time work. In our data, however, male part-time work is negligeable.
} 


$$
\begin{gathered}
\max _{h^{f}, h^{m}, C^{f}, C^{m}} U^{f}\left[1-h^{f}, C^{f}\right] \\
U^{m}\left[1-h^{m}, C^{m}\right] \geq \bar{u}^{m}\left(w_{f}, w_{m}, y\right) \\
C=w_{f} \cdot h^{f}+w_{m} \cdot h^{m}+y \\
0 \leq h^{f} \leq 1, \quad h_{m} \in\{0,1\}
\end{gathered}
$$

The function $\bar{u}^{m}\left(w_{f}, w_{m}, y\right)$ defines the level of utility that member $m$ can command when the relevant exogenous variables take the values $w_{f}, w_{m}, y$ though the analysis can be conditioned on any other exogenous variable. Underlying the determination of $\bar{u}^{m}$ is some allocation mechanism (such as a bargaining model) that leads to Pareto efficient allocations. We do not need to be explicit about such a mechanism; hence the collective model does not rely on specific assumptions about the precise way that couples share resources.

Also, note that, in general, we allow $\bar{u}^{m}$ to depend on the husband's wage even when the latter does not work. The idea, here, is that within a bargaining context, his threat point may well depend on the wage he would receive if he chose to work. If so, most cooperative equilibrium concepts will imply that $\bar{u}^{m}$ is a function of both wages and non labor income; in each case, indeed, a change in one of the threat points does modify the outcome. Regarding non-cooperative models of bargaining, various situations are possible. In some cases, for instance, the outcome does not depend on the threat points, which rules out any dependence of this kind. More interesting is the suggestion of MacLeod and Malcomson(1993), where the outcome of the relationship remains constant when the threat points are modified, unless one individual rationality constraint becomes binding; then the agreement is modified so that the resulting outcome "follows" the member's reservation utility along the 
Pareto frontier. ${ }^{10}$ In our context, this implies that among all households where $m$ is not working, only some will exhibit the dependence on $m$ 's wage. Finally, note that preferences (and the Pareto weights) are allowed to depend on taste shifter variables, such as age etc.

\subsubsection{The participation decision: who gains, who looses?}

In the standard, unitary framework, the participation decision is modeled in terms of a reservation wage. At this wage, the agent is exactly indifferent between working and not working. Generalizing this property to our setting is however tricky, since now two people are involved. The most natural generalization of the standard model is to define the reservation wage by the fact that one member (say, the member at stake, here the husband) is indifferent between working and not working. An important remark is that, in this case, Pareto efficiency requires that both members are indifferent. To see why, assume that the wife is not indifferent - say she experiences a strict loss if the husband does not participate. Take any wage infinitesimally below the reservation wage, and consider the following change in the decision process: the husband does work, and receives $\varepsilon$ more (of the consumption good) than previously planned. The husband is better off, since he was indifferent and he receives the additional $\varepsilon$; and if $\varepsilon$ is small enough, the wife is better off too, since the $\varepsilon$ loss in consumption is more than compensated by the discrete gain due to his participation.

In the remainder, we shall use the 'double indifference' assumption, that can be formally stated as follows:

\footnotetext{
${ }^{10}$ This will typically be the case for a generalization of the Nash bargaining concept to the case in which the relationship is non binding, in the sense that each member may at each period choose to leave. See Ligon (2002) for an axiomatic approach of dynamic Nash bargaining in a household context.
} 
Definition and Lemma DI ('double indifference'): The participation frontier $L$ is such that member $m$ is indifferent between participating or not. Pareto efficiency then implies that $f$ is indifferent as well.

Technically, this amounts to assuming that in the program (1) above, $\bar{u}^{m}$ is a continuous function of both wages and non labor income. Natural as it may seem, this continuity assumption still restricts the set of possible behavior (and, as such, plays a key role for deriving restrictions).

A possible, quite general interpretation is that the household first agrees on some general 'rule' that defines, for each possible price-income bundle, the particular (efficient) allocation of welfare across members that will prevail. Then this rule is "implemented" through specific choices, including $m$ 's decision to participate. Although the latter is assumed discrete, it cannot, by assumption, lead to discontinuous changes in each member's welfare, in the neighbourhood of the participation frontier; on the contrary, the participation frontier will be defined precisely as the locus of the price-income bundles such that $m$ 's drop in leisure, when participating, can be compensated exactly by a discontinuous increase in consumption that preserves smoothness of each member's well-being.

The double indifference assumption can be justified from an individualistic point of view. That both members should be indifferent sounds like a natural requirement, especially in a context where compensations are easy to achieve via transfers of the consumption good. Conversely, a participation decision entailing a strict loss for one member is likely to be very difficult to implement; all the more when the loss is experienced by the member who is supposed to start working. 


\subsubsection{The sharing rules}

It is well known that Pareto optima can be decentralized in an economy of this kind. Just as in Chiappori (1992), this property defines the central concept of the sharing rule. The important distinction here is that the decision of one of the members is discrete: the male can only decide to work or not.

Participation: Let us first consider the case when $m$ does participate. His utility is thus $U^{m}\left(C^{m}, 0\right)$, and we have that :

$$
U^{m}\left(C^{m}, 0\right)=\bar{u}^{m}\left(w_{f}, w_{m}, y\right)
$$

Solving for consumption $c^{m}$ we obtain

$$
C^{m}=V^{m}\left[\bar{u}^{m}\left(w_{f}, w_{m}, y\right)\right]=\Psi\left(w_{f}, w_{m}, y\right)
$$

where $V^{m}$ is the inverse of the mapping $U^{m}(., 0)$. Function $\Psi\left(w_{f}, w_{m}, y\right)$ is called the sharing rule. Now, Pareto efficiency is equivalent to $f$ 's behavior being a solution of the program:

$$
\begin{gathered}
\max _{h^{f}, C^{f}} U^{f}\left[1-h^{f}, C^{f}\right] \\
C^{f}=w_{f} \cdot h^{f}+y+w_{m}-\Psi\left(w_{f}, w_{m}, y\right) \\
0 \leq h^{f} \leq 1
\end{gathered}
$$

This generates a labor supply of the form :

$$
h^{f}\left(w_{f}, w_{m}, y\right)=H^{f}\left[w_{f}, y+w_{m}-\Psi\left(w_{f}, w_{m}, y\right)\right]
$$

where $H^{f}$ is the Marshallian labor supply function associated to $U^{f}$ which can be equal to zero if a corner solution arises.

A first consequence is that, for any $\left(w_{f}, w_{m}, y\right) \in P$ such that $h_{f}\left(w_{f}, w_{m}, y\right)>0$ : 


$$
\frac{1-\Psi_{w_{m}}}{1-\Psi_{y}}=\frac{h_{w_{m}}^{f}}{h_{y}^{f}} \equiv A\left(w_{f}, w_{m}, y\right)
$$

Note that, in the absence of unobserved heterogeneity in preferences, the function $h^{f}$, and hence the ratio $A$, are empirically observable. Hence (5) provides a first restriction of $\Psi$.

Non participation: We now consider the non participation case. Then male's utility is $U^{m}\left(C^{m}, 1\right)$, and we have that :

$$
U^{m}\left(C^{m}, 1\right)=\bar{u}^{m}\left(w_{f}, w_{m}, y\right)=V_{m}^{-1}\left(\Psi\left(w_{f}, w_{m}, y\right)\right)
$$

which can be inverted in :

$$
C^{m}=W^{m}\left[V_{m}^{-1}\left(\Psi\left(w_{f}, w_{m}, y\right)\right)\right]=F\left(\Psi\left(w_{f}, w_{m}, y\right)\right)
$$

where $W^{m}$ is the inverse of the mapping $U^{m}(., 1)$ and where $F=W^{m} \circ\left(V^{m}\right)^{-1}$ is increasing because both $V^{m}$ and $W^{m}$ are increasing.

As before, f's decision program leads to a labor supply of the form :

$$
h^{f}\left(w_{f}, w_{m}, y\right)=H^{f}\left[w_{f}, y-F\left(\Psi\left(w_{f}, w_{m}, y\right)\right)\right]
$$

and, for any $\left(w_{f}, w_{m}, y\right) \in N$ such that $h_{f}\left(w_{f}, w_{m}, y\right)>0$ :

$$
\frac{-F^{\prime} \Psi_{w_{m}}}{1-F^{\prime} \Psi_{y}}=\frac{h_{w_{m}}^{f}}{h_{y}^{f}}=B\left(w_{f}, w_{m}, y\right)
$$

Note that in contrast to the unitary model $f$ 's labor supply will depend on $m$ 's (potential) wage even when $m$ is not working, because the decision process will vary with $w_{m} \cdot{ }^{11}$

It should finally be stressed that the function $A$ (respectively $B$ ) is defined only on $P$ (respectively $N$ ), i.e. for the set of wages and non-labor incomes for which

\footnotetext{
${ }^{11}$ See Neary and Roberts (1980) on shadow prices when a good is at a corner.
} 
the male works (does not work). Moreover functions $A$ and $B$ are only defined when the female works.

\subsubsection{The participation decision}

The participation frontier $L$ is defined by the set of wages and non-labor income bundles $\left(w_{f}, w_{m}, y\right) \in L$, for which $m$ is indifferent between participating or not:

Lemma 1 The participation frontier $L$ is characterized by

$$
\forall\left(w_{f}, w_{m}, y\right) \in L, \quad \Psi\left(w_{f}, w_{m}, y\right)-F\left(\Psi\left(w_{f}, w_{m}, y\right)\right)=w_{m}
$$

Proof. Since, on $L, f$ is also indifferent between $m$ participating or not participating, it must be the case that f's income does not change discontinuously in the neighborhood of the frontier. Since total income does change in a discontinuous way (net increase of $w_{m}$ when $m$ participates), it must be the case that the whole gain goes to $m$.

The Lemma shows that at the participation frontier all additional income from participation goes to $m$ to compensate him for the discrete increase in his labour supply. This is a property that depends on all goods being private and may not hold in the presence of public goods as we discuss in the last section -(Extensions)

To parameterize $L$, we choose to use a shadow wage condition; i.e., $m$ participates if and only if

$$
w_{m}>\gamma\left(w_{f}, y\right)
$$


for some $\gamma$, that describes the frontier. Note that this reservation wage property does not stem from the theoretical set-up as in standard labor supply models, but has to be postulated. This will be true if (10) has a unique solution for $w_{m}$, a sufficient condition for which is that it is a contraction mapping: ${ }^{12}$

Assumption R : The sharing rules are such that

$$
\forall\left(w_{f}, w_{m}, y\right), \quad \mid\left[1-F^{\prime}\left(\Psi\left(w_{f}, w_{m}, y\right)\right] . \Psi_{w_{m}}\left(w_{f}, w_{m}, y\right) \mid<1\right.
$$

In this case whenever $h^{f}>0, \gamma$ is characterized by the following equation :

$$
\left.\forall\left(w_{f}, y\right), \quad \Psi\left(w_{f}, \gamma\left(w_{f}, y\right), y\right)\right)-F\left(\Psi\left(w_{f}, \gamma\left(w_{f}, y\right), y\right)\right)=\gamma\left(w_{f}, y\right)
$$

which implies:

$$
\begin{gathered}
\left(\Psi_{y}+\gamma_{y} \Psi_{w_{m}}\right)=\frac{\gamma_{y}}{\left(1-F^{\prime}\right)} \\
\Psi_{w_{f}}=\frac{\gamma_{w_{f}}}{\gamma_{y}} \Psi_{y}
\end{gathered}
$$

In the second equation, the relative effect of $w_{f}$ and $y$ on the participation frontier is equal to their relative effect in the sharing rule since it is only through that function that those variables affect male participation. In contrast, in the first equation, it is the absolute level of the effect of $y$ that allows identification of the first derivative of the utility difference $\left(F^{\prime}\right)$ conditional on the sharing rule. Equations (5) and (9) complete the system as shown next.

\footnotetext{
${ }^{12}$ In words consider the increase in $m$ 's consumption resulting from an infinitesimal increase $d w_{m}$ in $m$ 's wage. When $m$ is participating, $d w_{m}$ increases both the household income and $m$ 's bargaining power, while the first effect does not operate when $m$ does not participate. Let $d c^{m}$ denote the consumption change in the former case, and $d c^{m *}$ in the latter. Then (11) states that the difference $d c^{m}-d c^{m *}$ cannot be more than the initial increase $d w_{m}$.
} 


\subsubsection{Restrictions from the Collective Model}

What are the restrictions implied by the collective setting just described with private consumption? And is it possible to recover the structural model - i.e., preferences and the sharing rules - from observed behavior?

Proposition 2 Under the conditions listed in the Appendix

(i) the collective model with private commodities leads to restrictions on household behavior. In particular on the frontier when she participates (i.e. for the set of $w_{f}, w_{m}$ and $y$ such that $w_{m}=\gamma\left(w_{f}, y\right)$ and $\left.h^{f}>0\right)$ we have that

$$
\begin{array}{cc}
-\Psi_{w_{m}}+A \Psi_{y}= & A-1 \\
-\Psi_{w_{m}}+B \Psi_{y} & =\frac{B}{F^{\prime}} \\
\gamma_{y} \Psi_{w_{m}}+\Psi_{y}= & \frac{\gamma_{y}}{\left(1-F^{\prime}\right)} \\
\Psi_{w_{f}}= & \frac{\gamma_{w_{f}}}{\gamma_{y}} \Psi_{y}
\end{array}
$$

(ii) the preferences and the sharing rules can be recovered up to an additive constant everywhere where $h_{f}>0$.

Proof: (i) We have assumed that $\bar{u}^{m}\left(w_{f}, w_{m}, y\right)$ is continuously differentiable everywhere. It follows that both (5) and (9) are valid on the frontier as well. Hence, on the frontier, using (5), (9) and (13) the sharing rule is determined by (14).

(ii) The proof follows in stages. First we consider the restrictions which recover the sharing rule and $F^{\prime}$ on the participation frontier. This is followed by a proof of identification outside the frontier. Identification of preferences then follows. See Appendix. Below we use these restrictions to derive direct tests of the collective model.

These conditions can be interpreted as follows. The first condition is standard in the collective framework; it expresses the fact that when he is working, his 
wage affects her labor supply only through an income effect. The second condition reflects the 'structural stability' implied by the collective setting. It states that what is determined by the couple's decision process is the utility $\bar{u}^{m}\left(w_{f}, w_{m}, y\right)$ he would reach for each wage-income bundle; this utility level being implemented by different consumption levels depending on whether he works or not. Finally, the last two conditions reflect the 'double indifference' property; they state that the participation frontier is such that both he and she are indifferent between his working and not working.

\subsection{Unitary Model Restrictions}

In the previous sections, we have derived the conditions that the labor supply functions of the female $f$ and the participation frontier of the male $m$ must satisfy to be compatible with the collective setting, when all goods are private. We now contrast this result to the unitary framework and discuss the extent to which the two models provide different predictions and testable implications that would allow us to discriminate between the two hypotheses. Here, the household, as a whole, is assumed to maximize some unique utility function $U^{H}$, subject to the standard budget constraint :

$$
\begin{gathered}
\max _{h^{f}, h^{m}, C} U^{H}\left[1-h^{m}, 1-h^{f}, C\right] \\
C=w_{f} \cdot h^{f}+w_{m} \cdot h^{m}+y \\
0 \leq h^{f} \leq 1, \quad h^{m} \in\{0,1\}
\end{gathered}
$$

Two points are worth mentioning here:

- We do not impose separability. This means that the household's preferences for $f$ 's leisure and total consumption may in general depend on whether $m$ 
is working or not. Let $V^{W}$ and $V^{N}$ (respectively. $h_{W}^{f}$ and $h_{N}^{f}$ ) denote the corresponding indirect utility functions when he works and when he does not ( respectively female labor supply).

- Preferences, here, only depend on total consumption $C$; we do not introduce $C^{f}$ and $C^{m}$ independently. This is a direct consequence of Hicks composite commodity theorem: since $C^{f}$ and $C^{m}$ have identical prices, they cannot be identified in this general setting.

When she participates $\left(h^{f}>0\right)$, one can immediately derive two restrictions, namely :

$$
\frac{\partial h_{W}^{f}}{\partial w_{m}}=\frac{\partial h_{W}^{f}}{\partial y} \quad \text { Male Works }
$$

and

$$
\frac{\partial h_{N}^{f}}{\partial w_{m}}=0 \quad \text { Male does not Work }
$$

These are standard restrictions in the unitary context. Equation (16) is the "income pooling" property : when $m$ 's number of hours (conditional on participation) are constrained, then a change in $w_{m}$ can only have an income effect upon $f$ 's labor supply. Equation (17), on the other hand, reflects the fact that the income effect of $m$ 's wage must be zero when he is not working.

Finally, $m$ 's participation decision depends on the difference between the household's (indirect) utility when he is working and when he is not :

$$
h^{m}=1 \Leftrightarrow V^{W}\left(w_{f}, y+w_{m}\right) \geq V^{N}\left(w_{f}, y\right)
$$

In particular, the participation frontier is characterized by :

$$
V^{W}\left(w_{f}, y+\gamma\left(w_{f}, y\right)\right)=V^{N}\left(w_{f}, y\right)
$$


Differentiating and using Roy's identity gives that, on the frontier :

$$
\frac{\partial \gamma}{\partial w_{f}}=h_{N}^{f}-h_{W}^{f}+h_{N}^{f} \frac{\partial \gamma}{\partial y}
$$

The last term on the right hand side corresponds to a standard income effect: a marginal increase $d w_{f}$ of female wage has the same first order effect upon participation as an increase of household non labor income equal to $h_{N}^{f} d w_{f}$. In addition, it also affects the cost of male participation due to the reduction of female working time; this corresponds to the term in $h_{N}^{f}-h_{W}^{f}$.

We can summarize these findings as follows :

Proposition 3 The functions $\gamma, h_{P}^{f}$ and $h_{N}^{f}$ are compatible with the unitary model if and only if conditions (16), (17) and (18) are satisfied.

\subsection{The separable unitary model}

To conclude this discussion we ask what happens when, within the unitary setting, we introduce the same separability assumption as in the collective case? Formally, this amounts to assuming that

$$
U^{H}\left[1-h^{m}, 1-h^{f}, C^{m}, C^{f}\right]=U^{H}\left[U^{m}\left(1-h^{m}, C^{m}\right), U^{f}\left(1-h^{f}, C^{f}\right)\right]
$$

where $U^{m}$ and $U^{f}$ are interpreted as individual utility functions. Note that, in this case, one can introduce $C^{m}$ and $C^{f}$ (instead of their sum), since the Hicksian composite good theorem no longer applies (see Chiappori (1988) for a precise statement).

In principle, this is a particular case of both the unitary model (since it corresponds to the maximization of a unique utility) and the collective model (since maximizing $U^{H}$ under budget constraint obviously generates Pareto efficient outcomes). The problem, however, is that the form is now very strongly constrained. 
To see how, consider the assumption made above that, on the Pareto frontier, both members are indifferent between participation and non participation. This need not be the case here; Interpreting the utility function from the perspective of the collective model, the maximization of $U^{H}$ may, and will in general, lead to participation decisions where one member is a strict loser, this loss being compensated (at the household level, as summarized by $U^{H}$ ) by a strict gain for the spouse. ${ }^{13}$ The key intuition is that, within the unitary setting, the marginal utility of income, as evaluated at the household level, is equated across members. This by no means implies that utility levels are compensated in any sense. One can expect that the additional income generated by the husband's participation will be partially distributed to the wife, who, because of the standard income effect, will both work less and consume more. This need not always be the case, though, because the husband's marginal utility of consumption is modified when he participates (unless, of course, his preferences are separable in leisure and consumption). But, in any case, there is no reason to expect bilateral indifference.

This provides an interesting illustration of the restrictive nature of the unitary model. From an individualistic point of view, that both members should be indifferent sounds like a natural requirement, especially in a context where compensations are easy to achieve via transfers of the consumption good. Conversely, a participation decision entailing a strict loss for one member is likely to be very difficult to implement. As it turns out, however, assuming a constant utility function essentially forbids an assumption of this kind; the model is not flexible enough with respect to the decision process to allow for such extensions.

\footnotetext{
${ }^{13}$ Of course within the unitary model it does not make sense to talk about gainers and loosers within the household, since the unit is the household and not its members.
} 


\section{Estimating Family Labor Supply}

\subsection{Data}

The data we use is drawn from the UK Family Expenditure Surveys from 1978 to the first quarter of 2001 inclusive. We restrict attention to households where both the male and the female are below 60 and the male over 22 . We further restrict the sample to include households where the female is over 35 . This allows us to focus on those households whose children have either left or who are unlikely to have children rather than on households who may still be planning children. Our households represent between $10 \%$ and $12 \%$ of the population of all households, including singles, where the head is 23-59 years old. They also represent between 13\%-20\% of all couples (married or co-habiting) with a head in that age range. This proportion has been increasing, reflecting the decline in fertility. We exclude the self-employed, since their hours of work are not measured. ${ }^{14}$ The analysis should be viewed as pertaining to this sub-population. All monetary values are deflated by the UK retail price index and are expressed in 2001 prices.

\subsection{Specification and Identifying assumptions}

The discussion up to now sets up the model without unobserved heterogeneity. Allowing for unobserved heterogeneity together with nonparticipation complicates matters and raises the issue of identifiability of the model from available data. The complications are compounded by the fact that preference heterogeneity will also reflect itself in the sharing rule. This is why, building upon the empirical labor supply literature (see Blundell and MaCurdy, 1999), we write a simple but already

\footnotetext{
${ }^{14}$ Other selections to eliminate extreme outliers and influential observations are the following: We exclude all those who report leaving full time education before 10 years of age, all those with asset income of more than $£ 1000$ a week in real terms and all those whose total nondurable consumption per week is $£ 1000$ a week below total household weekly earnings.
} 
rich model where all structural functions (labour supply and sharing rule) are semilog linear and additive in the heterogeneity terms and where wages are endogenous. In estimation we assume that the vector of random terms are multivariate normal. ${ }^{15}$ We discuss the exclusion restrictions in the empirical analysis below.

We now write the equations of female hours, male participation and male and female wages. These equations are "semi-structural" in the sense that the sharing rule has been replaced by its expression as a function of wages, income and other exogenous variables though wages are endogenous.

\subsubsection{Female hours of work:}

A semi-log specification for female labour supply is a popular form to use on British data (see Blundell, Duncan and Meghir (1998) for example) and is never rejected by our data. Interaction effects have not proved to be important. Thus we write

$$
\begin{aligned}
h_{i t}^{f}= & A_{0 t}^{f}+A_{m} w_{i t}^{m}+A_{f} \log w_{i t}^{f}+A_{y} y_{i t}+ \\
& A_{4} e d u c_{i t}^{f}+A_{5} a g e_{i t}^{f}+A_{6} e d u c_{i t}^{m}+A_{7} a g e_{i t}^{m}+u_{1 i t}
\end{aligned}
$$

where $f$ denotes female and $m$ denotes male, $w_{i t}^{f}$ denotes the hourly wage rate for the female and $w_{i t}^{m}$ denotes the weekly earning for the male, $y_{i t}$ denotes other household (non-labor) income. We use the level of male earnings, rather than the $\log$, since this allows us to nest the income pooling hypothesis, where $A_{m}=A_{y}$. The variable $e d u c^{i}$ denotes education of member $i$, measured as the age that the person left full time education. Note that preferences are allowed to depend on the age and education of both partners as well as on cohort (or equivalently time effects as expressed by the inclusion of $A_{0 t}^{f}$ ). These factors may affect preferences for work directly, or indirectly through the sharing rule.

\footnotetext{
${ }^{15}$ In the working paper version we show that the model is semiparametrically identified i.e. given the exclusion restrictions and a joint iid assumption for the vector of errors no distributional assumption is required. See http://www.ifs.org.uk/workingpapers/wp0119.pdf
} 
The parameters of the labor supply function will be different, depending on whether the male is working or not. Let (19) represent the labor supply function when the male is working. When he is not, the labor supply function is given by:

$$
\begin{aligned}
& h_{i t}^{f}=\quad a_{0 t}^{f}+a_{m} w_{i t}^{m}+a_{f} \log w_{i t}^{f}+a_{y} y_{i t}+ \\
& d_{t}^{0}+a_{4} e d u c_{i t}^{f}+a_{5} a g e_{i t}^{f}+a_{6} e d u c_{i t}^{m}+a_{7} a g e_{i t}^{m}+u_{0 i t}
\end{aligned}
$$

\subsubsection{Male participation:}

The latent index for male participation is also assumed semi-log linear:

$$
\begin{aligned}
p_{i t}^{m}= & b_{p t}^{m}+b_{m}^{m} w_{i t}^{m}+b_{f}^{m} \log w_{i t}^{f}+b_{y}^{m} y_{i t}+ \\
& \zeta_{4} e d u c_{i t}^{f}+\zeta_{5} a g e_{i t}^{f}+\zeta_{6} e d u c_{i t}^{m}+\zeta_{7} a g e_{i t}^{m}+u_{i t}^{m}
\end{aligned}
$$

where $p_{i t}^{m}$ is positive for male participants and negative (or zero) otherwise.

One can solve simply for $w_{i t}^{m}$ when $p_{i t}^{m}=0$ to derive the male reservation earnings and the parameters of the frontier of participation. These are:

$$
\gamma_{f}=-\frac{b_{f}^{m}}{b_{m}^{m}} \quad \gamma_{y}=-\frac{b_{y}^{m}}{b_{m}^{m}}
$$

Because of the sharing rule the male participation equation and the two female labor supply equations will depend, in general, on the same set of variables.

\subsubsection{Wage equations:}

We take a standard human capital approach to wages. However, we do not restrict the relative prices of the various components of human capital to remain constant over time. Hence

$$
\begin{aligned}
& w_{i t}^{m}=\alpha_{0 t}^{m}+\alpha_{1 t}^{m} e d u c_{i t}^{m}+\alpha_{2 t}^{m} a g e_{i t}^{m}+\alpha_{2 t}^{m}\left(a g e_{i t}^{m}\right)^{2}+u_{w i t}^{m} \\
& \log w_{i t}^{f}=\alpha_{0 t}^{f}+\alpha_{1 t}^{f} e d u c_{i t}^{f}+\alpha_{2 t}^{f} a g e_{i t}^{f}+\alpha_{2 t}^{f}\left(a g e_{i t}^{f}\right)^{2}+u_{w i t}^{f}
\end{aligned}
$$


Note that wages do not depend on the characteristics of the partner. All coefficients are time varying reflecting changes in the aggregate price of each component of human capital.

\subsubsection{Non-labor income}

We measure non-labor income as the difference between consumption and total household earnings, i.e. $y_{i t}=$ consumption $-w_{i t}^{f} h_{i t}^{f}-w_{i t}^{m} p_{i t}^{m}$. This approach reduces measurement error and accounts for sources of wealth that we do not observe but that matter for individual decisions, including pension wealth. ${ }^{16}$ This measure of unearned income is treated as endogenous and we use predictions based on the reduced form equation,

$$
\begin{aligned}
& y_{i t}=\alpha_{0 t}^{y}+\alpha_{1 t}^{y} e d u c_{i t}^{y}+\alpha_{2 t}^{y} a g e_{i t}^{m}+\alpha_{3 t}^{y}\left(a g e_{i t}^{m}\right)^{2}+\alpha_{4 t}^{y} a g e_{i t}^{f}+\alpha_{5 t}^{y}\left(a g e_{i t}^{f}\right)^{2} \\
& +a_{6 t}^{y} \mu_{i t}+a_{7 t}^{y} \mu_{i t}^{2}+a_{8 t}^{y} \mu_{i t}^{2}+\sum_{k=1}^{3} a_{8+k}^{y} 1\left(\mu_{i t}-s_{k}>0\right)\left(\mu_{i t}-s_{k}\right)^{3}+a_{12}^{y} 1\left(\mu_{i t}>0\right)+u_{y i t}
\end{aligned}
$$

where $\mu_{i t}$ is asset income not including any welfare payments or other government transfers. Thus the instrument used here is asset income interacted with time (see the time varying coefficients) as well as education and age interacted with time as above. We have included the polynomial and spline terms in $\mu_{i t}$ as well as an indicator for non-zero asset income to improve the fit of this reduced form.

\subsubsection{Stochastic specification and exclusion restrictions}

We assume that all error terms $\left(u_{1 i t}^{f}, u_{0 i t}^{f}, u_{i t}^{m}, u_{w i t}^{m}, u_{w i t}^{f}, u_{y i t}\right)$ are jointly conditionally normal with constant variance (and independent of education, age, other income and time). The basic exclusion restriction written in the labour supply equations above is that education-time interactions and age-time interactions are

\footnotetext{
${ }^{16}$ See MaCurdy (1983), Blundell and Walker (1986), Arellano and Meghir (1992) and Blundell, Duncan and Meghir (1998) amongst others.
} 
excluded from these equations, implying that differences in the preferences and the sharing rule across education groups remain constant over time. Hence, identification of labour supply of both partners does not rely on excluding education. It relies on the way that the returns to education have changed (see, Blundell, Duncan and Meghir, 1998). The rank condition for identification is that wages have changed differentially across education groups over time. That they have done so in the UK is a well established fact (for men see Gosling, Machin and Meghir, 2000).

In addition we need to assume that any changes in the institutional framework has not affected the sharing rule or the composition of those households differentially across education groups. The changing structure of benefits in particular can affect the structure of the sharing rule, since it changes the outside option for the two partners. If this is the case differentially across education groups then the cohort-time-education interactions would not be excludable. It is part of our identifying assumptions that the sharing rule (as well as preferences) have not changed differentially across these groups. One key concern may be changes in the divorce laws. The most important change in the law came in 1969 - nine years before the start of our data. This had an immediate and large impact on the number of divorces. However since the start of our sample divorces have remained more or less constant. Nevertheless we still need to assume that other institutional changes have not changed preferences and sharing rules differentially across education groups. However, we do allow for a general time effects in preferences and the sharing rule by including time dummies in the model, as well as permanent differences across education groups. Together with the age effects this allows for differences across cohorts which will reflect the impact of the institutional changes or other changes such as fertility differences across cohorts 


\subsubsection{Restrictions from the Collective and Unitary Models}

Using the family labor supply specification (19), (20) and (22), the restrictions on the collective model derived from Proposition 1 may be written (see working paper)

$$
\begin{array}{cc}
\frac{A_{m}-a_{m}}{A_{y}-a_{y}}=-\frac{1}{\gamma_{y}} \quad(I) \\
\frac{A_{f}-a_{f}}{A_{y}-a_{y}}=\frac{\gamma_{f}}{\gamma_{y}} \quad(I I)
\end{array}
$$

It is interesting to contrast these restrictions with the structural restrictions that would be derived in the unitary case. Using the same notation (upper and lower cases for the two regimes), we have to impose equations (16), (17) and (18) on the frontier $\left(w_{m}=\gamma_{f} \log w_{f}+\gamma_{y} y+z \gamma_{z}\right)$. The first two yield:

$$
\begin{gathered}
A_{m}=A_{y} \quad(I) \\
a_{m}=0 \quad(I I)
\end{gathered}
$$

Using (18), the definition of the frontier and these two restrictions give:

$$
\gamma_{f}=\left(1+\gamma_{y}\right)\left(a_{f} \log w_{f}+a_{y} y\right)-\left(A_{f} \log w_{f}+A_{y}\left(y+w_{m}\right)\right)
$$

As this equation is valid only on the frontier for any $w_{f}$ and $y$, it is also an equation of the frontier. Therefore, the following vectors are colinear:

$$
\left(\begin{array}{l}
1 \\
-\gamma_{f} \\
-\gamma_{y}
\end{array}\right),\left(\begin{array}{l}
-A_{y} \\
\left(1+\gamma_{y}\right) a_{f}-A_{f} \\
\left(1+\gamma_{y}\right) a_{y}-A_{y}
\end{array}\right)
$$

Hence in the unitary model we have two additional restrictions, namely:

$$
\begin{gathered}
\left(1+\gamma_{y}\right)\left(a_{y}-A_{y}\right)=0 \\
A_{y} \gamma_{f}=\left(1+\gamma_{y}\right) a_{f}-A_{f} .
\end{gathered}
$$




\subsection{Estimation}

First we estimate two reduced form participation equations: One for men and one for women. These are obtained by substituting out the wages from the structural participation equations. The resulting equations have the form

$$
p_{i t}^{k}=\begin{gathered}
\beta_{0 t}^{k}+\beta_{1 t}^{k} e d u c_{i t}^{f}+\beta_{2 t}^{k} a g e_{i t}^{f}+\beta_{3 t}^{k}\left(a g e_{i t}^{f}\right)^{2}+ \\
\beta_{4 t}^{k} e d u c_{i t}^{m}+\beta_{5 t}^{k} a g e_{i t}^{m}+\left(\beta_{6 t}^{k} a g e_{i t}^{m}\right)^{2}+\beta_{7 t}^{k} y_{i t}+v_{i t}^{k}, \quad k=m, f
\end{gathered}
$$

Thus we include all variables that determine wages of men and women as well as other income $y_{i t}$, and we allow the coefficients to change over time. The changes in the coefficients for variables that determine wages reflect the changing coefficients in the wage equations. ${ }^{17}$

We then estimate the female log hourly wage equation and the male weekly earnings equations including the inverse Mill's ratio obtained from the estimated participation equations (27). In this parametric approach the wage equation is identified from the exclusion of other income and the spouse's characteristics as well as from the normality assumption. ${ }^{18}$

Using the estimated wage equations we impute offered wages for all individuals in the data set. The participation frontier is then estimated using a probit, which includes other income, the imputed wages, time effects, age and education.

The likelihood function for female labor supply when the man is working is and when there are $n_{W}$ such observations

$$
\begin{aligned}
\log L^{W}= & \sum_{i=1}^{n_{W}}\left\{1\left(h_{i t}^{f}<0\right) \log \operatorname{Pr}\left(p_{i t}^{m}>0, h_{i t}^{f}<0\right)+\right. \\
& \left.1\left(h_{i t}^{f}>0\right)\left[\log \operatorname{Pr}\left(p_{i t}^{m}>0\right)+\log f\left(h_{i t}^{f} \mid p_{i t}^{m}>0\right)\right]\right\}
\end{aligned}
$$

\footnotetext{
${ }^{17}$ The changing coefficient on other income is not implied directly by the structure of the model (and it is not necessary for identification purposes). We allow this as an extra degree of flexibility.

${ }^{18}$ We tested for zero skewness in both the male earnings equation and in the female log hourly wage equation, taking into account the selection. The t-statistics were 1.93 and 1.38 respectively Hence the hypothesis is accepted in both cases.
} 


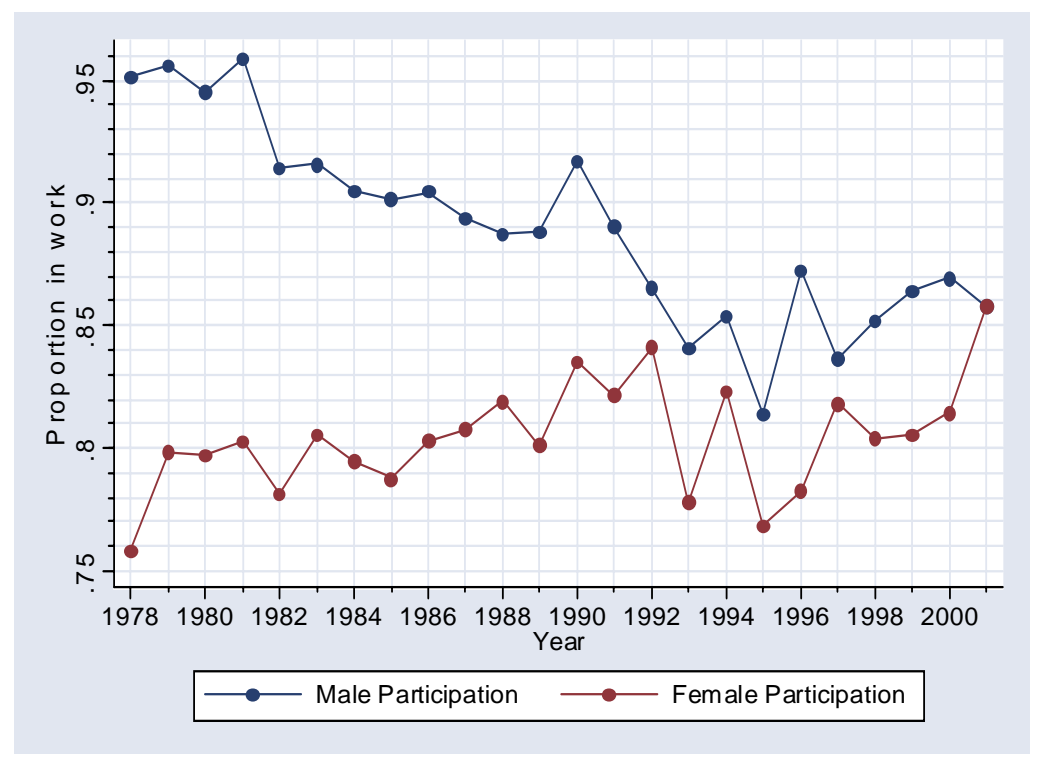

Figure 1: Proportion of married men and women employed by year

When the man is not working ( $n_{N}$ observations) this becomes

$$
\begin{aligned}
& \log L^{N}= \sum_{i=1}^{n_{N}}\left\{1\left(h_{i t}^{f}<0\right) \log \operatorname{Pr}\left(p_{i t}^{m}<0, h_{i t}^{f}<0\right)+\right. \\
&\left.1\left(h_{i t}^{f}>0\right)\left[\log \operatorname{Pr}\left(p_{i t}^{m}<0\right)+\log f\left(h_{i t}^{f} \mid p_{i t}^{m}<0\right)\right]\right\}
\end{aligned}
$$

In the above $f(\cdot)$ represents the conditional normal density function and 1(a) is the indicator function which is equal to one when $a$ is true and zero otherwise.

The labor supply estimates that are obtained from this procedure do not satisfy exactly the assumptions of the collective (or the unitary) model. We can then carry out a test of the null hypothesis that the coefficients can be rationalized using the unitary model and/or the collective model and derive the structural estimates.

\subsection{Basic facts in the data and the wage equations}

For this group of households there have been large changes in the male participation rates. On the other hand, participation has been relatively steady over these years 
for married women without children. This is shown in Figure 1. Male participation has dropped for most age groups across cohorts to a greater or lesser extent but is most larger for those over the age of 50, which is generally interpreted as an increase in early retirement. In figure 2 we show the life-cycle participation. Each line represents a separate date of birth cohort. The vertical distance between the lines shows the decline across cohorts and this is particularly pronounced at older ages. Declines in participation take place from about the age of 40 (see also Meghir and Whitehouse, 1997). Over the sample period there is no state pension available before the age of 60 for women and 65 for men; so this in itself, cannot explain the decline in participation at older ages or across cohorts. Of course older individuals will have more wealth than younger ones and some will be able to retire on Disability Benefit. Empirically we capture the effect of increased wealth by using a consumption based measure of non-labour income, which will be higher for those with more assets and hence more consumption. We also include age effects in the labour supply of both partners. However for a deeper treatment of this issue one would need to couch the collective model within a dynamic framework and deal directly with issues of commitment in dnamic settings and intertemporal allocations. ${ }^{19}$

The wage equations include age and years of education interacted with time. The participation equation contains in addition the education of both partners and other household income excluding any welfare benefits, all interacted with time. The p-values for all the female education terms in the male participation equation is $0.44 \%$ while just for the male education-time interactions the p-value is $1.5 \%$. The male education terms in the female participation equation have a joint $\mathrm{p}$-value of $0.62 \%$ and the time interactions alone $1.4 \%$. The p-value for the

\footnotetext{
${ }^{19}$ see Mazzoco (2003b) for a treatment of some of these issues.
} 


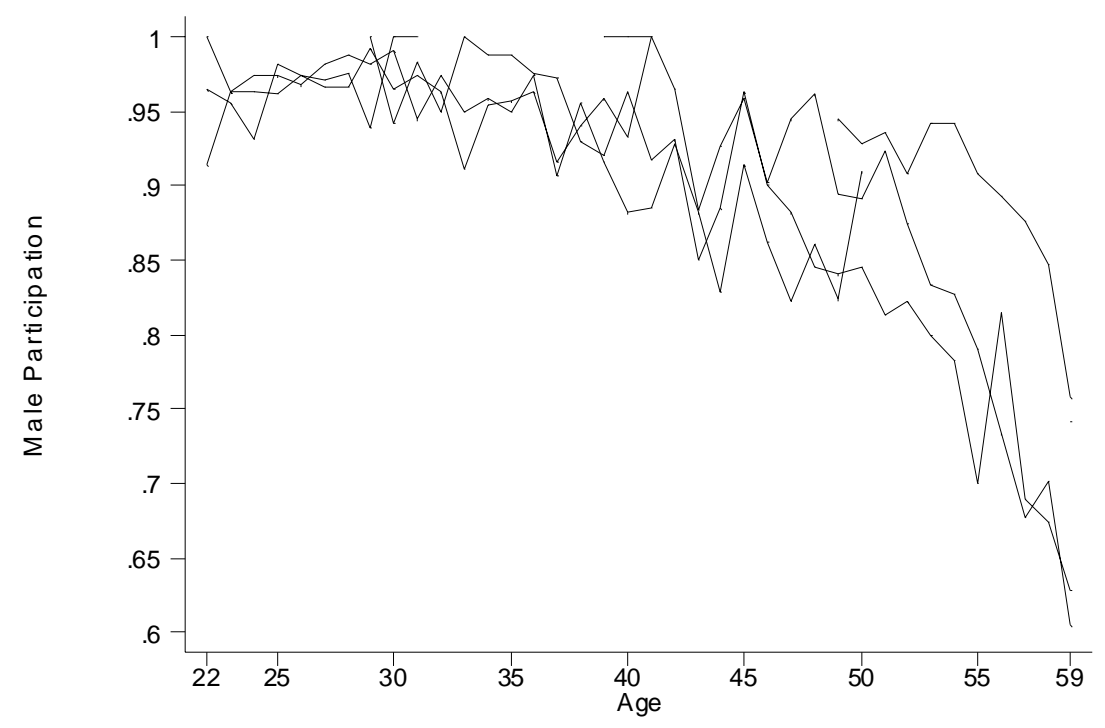

Figure 2: Male Participation over the life-cycle by cohort

unearned income terms in both participation equations is indistinguishable from 0 although there is less evidence that the effect varies over time since the p-value for the unearned income-time interactions is $15 \%$ in the male participation equation and $18 \%$ in the female one.

The effects of correcting for selection on aggregate predicted wages over time can be seen in Figure 3 for females (real log hourly wages) and in Figure 4 for males (real weekly wage in levels). In both cases participation evidently biases observed wages upwards quite substantially. However only male wage growth is biased by selection. This is due to the large changes in the composition of the male labour force as participation declined. The selection correction rate for women is about $8 \%$ throughout. For men it is about $5 \%$ in the earlier period when participation rates were higher and increased to about $10 \%$ when rates were lower. The high level of selection correction for men is consistent with the fact the least skilled dropped out of the labour market. 


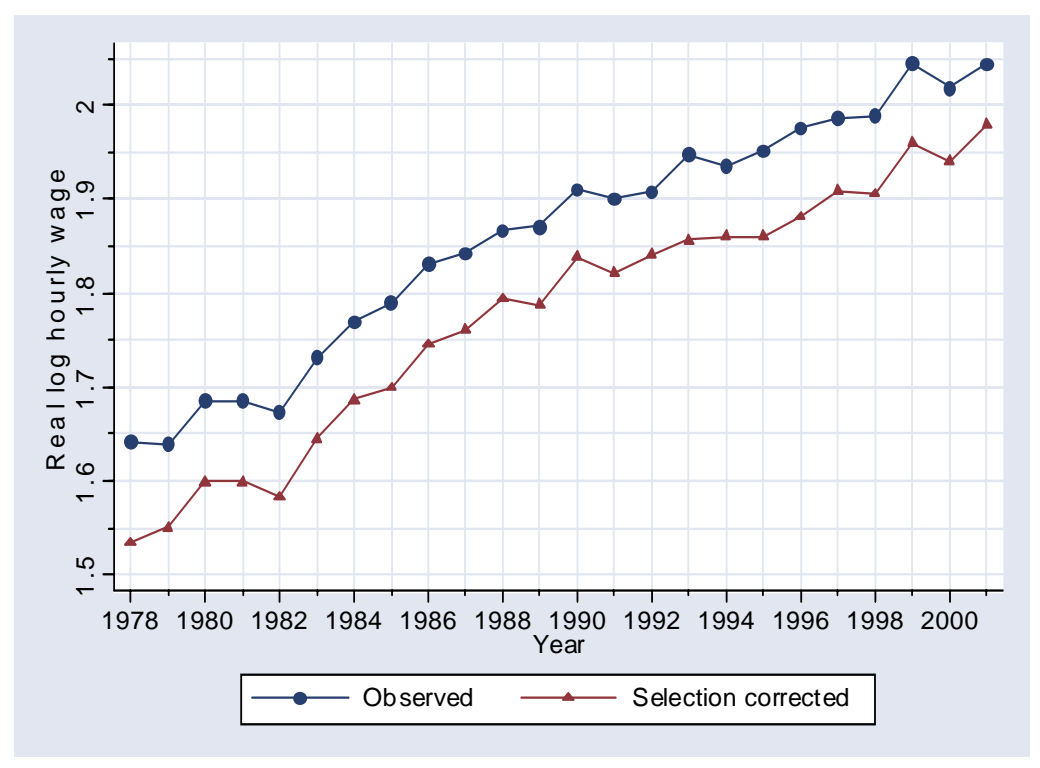

Figure 3: Actual and offered real log hourly wages for females by year

We now turn to the distribution of hours of work for those working. Women can be found working any number of hours from 1 to 55 and this can be seen in Figure 5. Hours of work for women with non-working husbands are on average lower by three hours and more dispersed. Men in contrast rarely if ever work below 35 hours a week (see Figure 6) and the distribution of their hours is very similar whether the female is working or not. For example the respective means are (standard deviations) are $42.7(8.6)$ and $42.9(9.1) .{ }^{20}$

We have also found in another data set information on weeks employed during the year. Of those working, 90\% work 52 weeks per year. This measure unfortunately ignores holidays, but this is unlikely to add much variability since these are quite standard. Moreover in the UK temporary layoffs are non-existent. Thus

\footnotetext{
${ }^{20}$ The reported histograms are for the whole sample period. The concentration beyond 35 hours is a feature in all years. Averages of male and female hours conditional on participation are quite stable over the period. Conditional standard deviations for women have increased a bit possibly reflecting the increased wage inequality. For men there has been an increase in the first few years. From then on the standard deviation of hours has not displayed any trend although it does fluctuate substantially from year to year.
} 


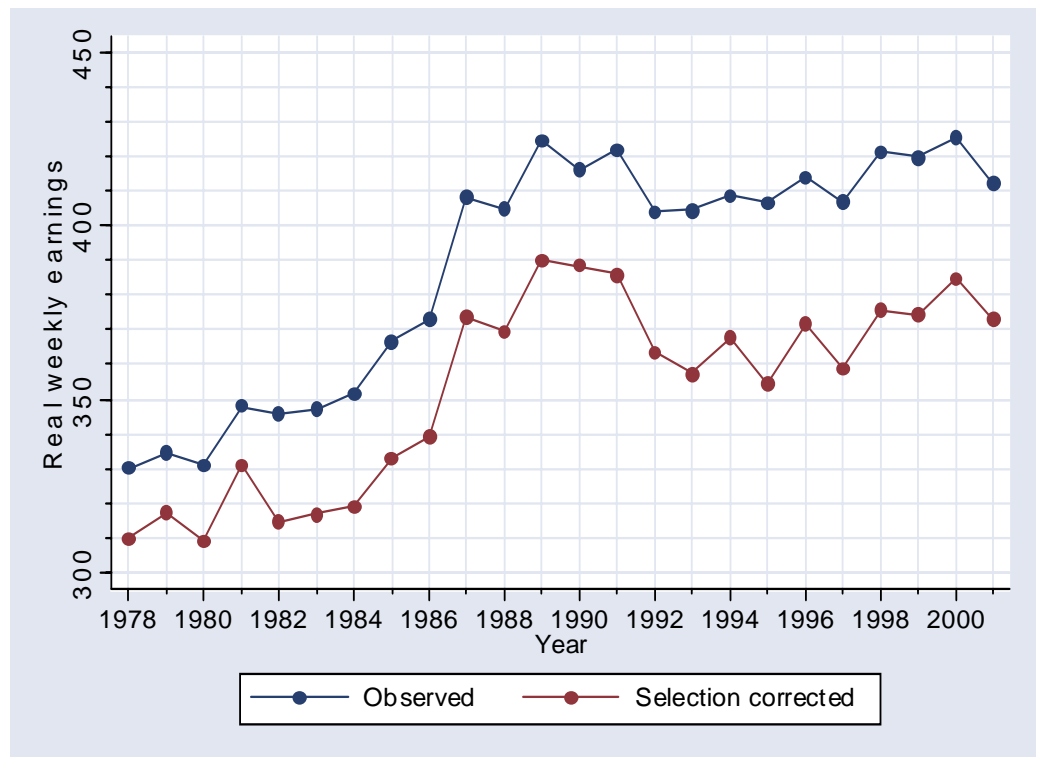

Figure 4: Actual and offered real male weekly wage by year

even in an annual dimension men seem to work full time or not at all. These facts motivated us to concentrate on the work - no work decision for males and not on their hours dimension; the actual hours outcome for males is an important question but we believe it relates to longer term occupational choices. The evidence that the distribution is not affected by female participation does not contradict the hypothesis that male hours conditional on participation are predetermined. Thus we leave the question of incorporating continuous variation of male hours above the 35 threshold for future research. Finally, average hours for workers fluctuate over time between 32 and 34 hour, but there is no apparent trend up or down. Neither is there any change in the shape of the distribution of hours of work.

\subsection{Testing the Unitary and Collective Models}

The unrestricted male participation and labour supply estimates are presented in

Table 2 in Appendix B. We impose a zero correlation between the participation 


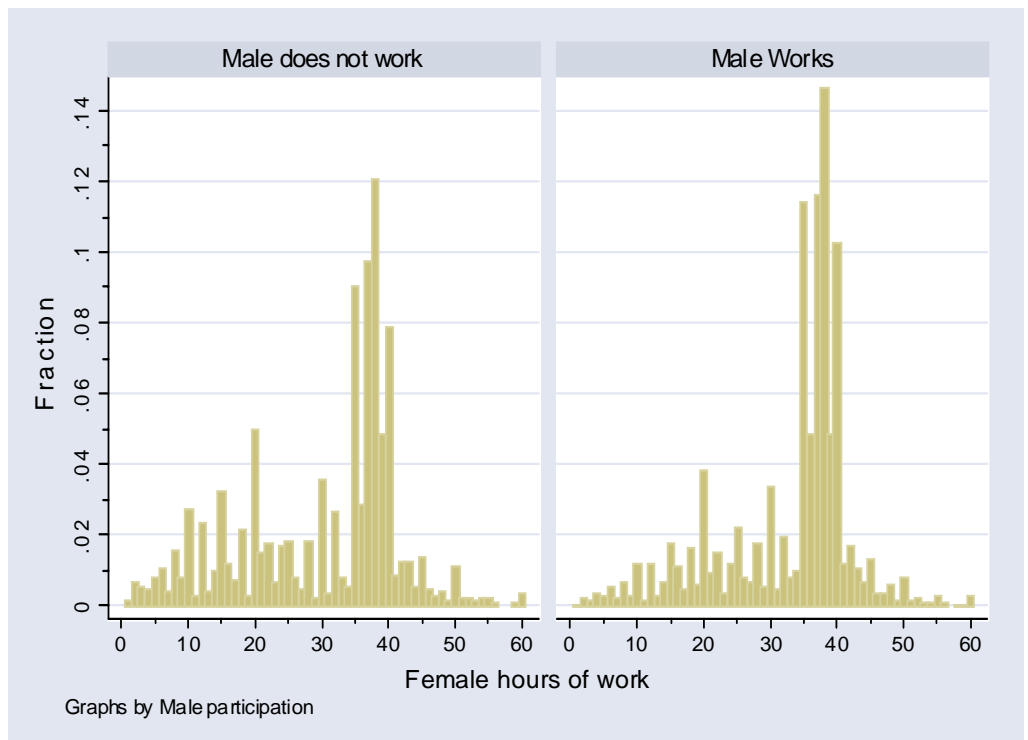

Figure 5: Female Hours of Work by male participation status

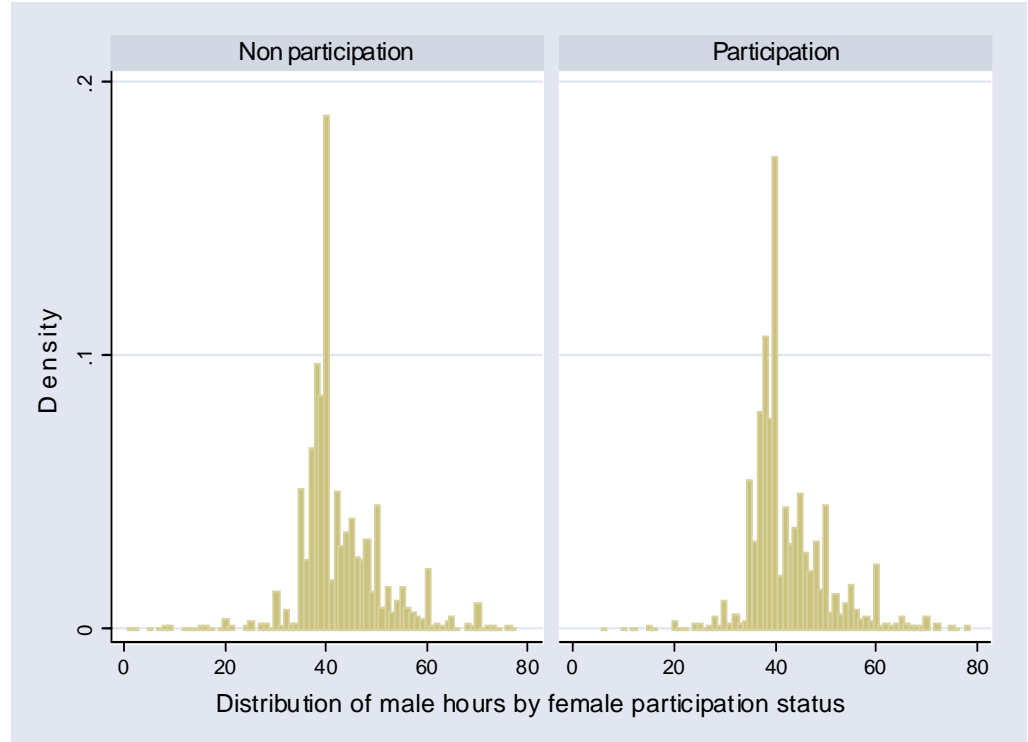

Figure 6: Male Hours of Work by female participation status 
equation and the labor supply equations in the two regimes (male works and male does not work). This was done since these correlations were very close to zero and insignificant. ${ }^{21}$ All equations include a full set of time dummies as well as male education and the age of both partners. The standard errors have been computed using the bootstrap and allowing for the fact that male and female wages as well as unearned income are predicted.

The own wage effect for female labour supply is positive, and larger when the male does not work. The interpretation of this, based on the collective model, is that when he does not work a marginal increase in her wage is appropriated to a greater extent by her than when he does work. The income effect is negative and again larger (in absolute value) when he does not work. Interestingly the effect of male wages on female labour supply when he does not work is positive with a p-value of $9.2 \%$ which, considering the low sample sizes for the case when the male does not work is quite a significant effect. This contradicts the standard unitary setting, but is implied by the collective model. Using minimum distance to jointly test this restriction together with the income pooling restriction (see equation 25 $I)$ and the restriction on income effects $(26 I)$ has a joint p-value of $2.8 \%$, clearly rejecting the unitary model.

On the other hand the two collective model restrictions (24) have a joint pvalue of $43 \%$ making them acceptable. ${ }^{22}$ We next impose the restrictions using unweighted minimum distance. The restricted estimates are presented in Table 1. These are estimates that satisfy the restrictions from the collective model, and from which it is possible to derive the sharing rule and the structural female labor supply and male participation frontier. The latter will be a function of her wage

\footnotetext{
${ }^{21}$ The correlation between male participation and female hours for working men is -0.016 (se 0.039 ). For non working men it is 0.044 (se 0.023).

${ }^{22}$ The first restriction gives a value of 1.69 with a standard error of 3.38. The second restriction is much tighter with a value of -0.29 and a standard error of 0.20 .
} 
and the other income she has access to.

As such, however, the estimates in Table 1 exhibit interesting patterns. The way the sign of the male wage effect on female labour supply changes with his work status is particularly noteworthy and can be given a bargaining interpretation: When he works, his wage has a negative influence on her labor supply. This is the standard income effect, operating through intrahousehold transfers: a increase in male wages, when the husband is working, augments the household's total income, and part of the enrichment is transferred to the wife. This income effect is large enough to dominate bargaining effects; note, in particular, that the effect of an increase in his wage when he works has the same sign as an increase in the household's non labor income, whether he works or not. ${ }^{23}$ However, when he is not working, the income effect of an increase in his wage vanishes. The only consequence of a wage increase is a change in respective bargaining powers, which must favor the husband. Consequently, we expect that he will attract a larger fraction of the (unchanged) household resources, and, by the same income effect as before, her labor supply should now increase. This intuition is exactly confirmed by the data. In addition the female wage effect is lower when he works than when he does not. The collective model interprets this as follows: When he works, for every pound that she earns she has to transfer an amount to him. This amount is lower when he does not work. Thus when he does not work an increase in the wage gives her a larger incentive to increase hours of work. This is an implication of equations (4), (8) and (11). It is particularly noteworthy that the patterns described above are present in the unrestricted estimates (see Table 2 in Appendix B) and have not been produced simply as a result of imposing the restrictions.

\footnotetext{
${ }^{23}$ That an increase in total non labor income should necessarily be distributed between members is a standard consequence of Nash-bargaining; see Chiappori and Donni (2005).
} 


\begin{tabular}{l|c|c|c|c|}
\hline \hline \multicolumn{2}{c|}{ Female Labour Supply - Restricted Estimates } \\
\hline \hline & \multicolumn{2}{|c|}{ Male Works } & \multicolumn{2}{c|}{ Male out of work } \\
\hline \hline male wage & -0.708 & 0.341 & 1.872 & 1.353 \\
Fem. log wage & 7.269 & 1.660 & 11.108 & 7.971 \\
other inc & -1.183 & 0.138 & -1.974 & 0.359 \\
\hline \hline \multicolumn{5}{|c|}{ Asymptotic standard errors in italics } \\
\hline \hline
\end{tabular}

Table 1: Restricted labour Supply estimates

\subsection{The Estimates of the Collective Model}

After imposing the restrictions above we check if a solution for the sharing rule exists. This depends on whether the quadratic equation

$$
\phi^{2}+\left(-a_{y}-A_{m}+a_{m}\right) \phi+A_{m} a_{y}-a_{m} A_{y}=0
$$

has a solution for $\phi$ (see Proposition 1). One, two or no solution may exist to equation $30 .^{24}$ In our case the estimates imply two solutions. Generically, only at most one of the solutions implies an integrable well behaved female labor supply. The solution shown below is the one that satisfies Slutsky negativity as well as assumption R.

The female labor supply implied by the estimates in the two samples we use is, up to a unidentified constant ${ }^{25}$

$$
h_{f}=\kappa_{f}+\underset{(25.57)}{21.43 \log w_{f}-} \begin{aligned}
& 3.59 y^{f} \\
& (1.05)
\end{aligned}
$$

where $y^{f}$ is the other income allocated to the female member of the household, after the male has been allocated his consumption. The income effect is precisely estimated but the female wage effect is badly determined. The implied wage elasticity is 0.66 while the income elasticity is 0.73 , both evaluated at sample means.

\footnotetext{
${ }^{24}$ Existence thus requires an additional (inequality) constraint that is verified here.

${ }^{25}$ In the equations that follow asymptotic standard errors are reported in brackets below the estimated coefficients.
} 
This labor supply satisfies the integrability conditions of individual utility maximization, which of course is a requirement of the theory.

The estimates of the labour supply function and the participation frontier can be used to derive the implied sharing rules for when the husband works and when he does not. This is of course a unique element of our approach, since it directly relates to the distribution of resources within the household. For couples with a working husband and for the two samples we consider these are

$$
\Psi=\kappa_{1}+\begin{aligned}
& 0.81 w_{m} \\
& (0.097)
\end{aligned}-\begin{aligned}
& 3.93 \log w_{f} \\
& (6.87)
\end{aligned}+\begin{aligned}
& 0.67 y \\
& (0.104)
\end{aligned}
$$

Thus an extra unit in male earnings implies an increase in his consumption by 0.81 units. He keeps 0.67 of a unit increase in household unearned income and he transfers 0.39 of a unit to her when her hourly wage rate increases by $10 \%$ ( 0.1 of a log point precisely), although this effect is not well determined. The sharing rule when he is not working is given by

$$
F(\Psi)=\kappa_{0}+\underset{(0.19)}{0.68} \begin{gathered}
\left(0.81 w_{m}\right. \\
(0.097)
\end{gathered}-\begin{gathered}
3.93 \log w_{f} \\
(6.87)
\end{gathered}+\begin{gathered}
0.67 y) \\
(0.104)
\end{gathered}
$$

and implies that al marginal increases get compressed by $68 \%$.

Thus the upshot of these results is that when he works, each tend to keep the larger part of marginal increases in their respective incomes and they share almost equally increases in unearned income, with him getting a bit extra. When he does not work he still obtains increases in consumption as his labour market opportunities improve but reduced to $68 \%$ of the previous values. The recent decline in male participation would have reduced overall resources for households but would also imply a shift in available resources towards the woman.

Finally, the implied participation frontiers based on the estimates for the two samples is

$$
w_{m}^{r}=\kappa_{m}+\underset{(0.21)}{0.29 y}-\underset{(2.64)}{1.69 \log w_{f}}
$$


but unfortunately the estimates are badly determined.

Since his consumption grows with other income, increases in the latter increase his reservation wage. However, increases in her wage reduce his consumption and hence make it more likely that he works.

\section{The Extension to Public Goods and Household Production}

\subsection{The Extension to Public goods}

Recent results show that an extension of the model to public consumption is feasible, although it may require additional information and/or particular assumptions. Not only are the main conclusions of the private good setting (i.e., identification and testability) preserved in the extended framework, but the current model can be interpreted, in this perspective, as the reduced form of the general problem, the emphasis being put here on private consumptions only. Although these developments are outside of the scope of the present paper, and will be the topic of future empirical investigations, one can indicate the general flavor of these extensions. We summarize the state of knowledge in this area which can be found in references made below and in Chiappori, Blundell and Meghir (2001).

There are several ways of introducing public consumption within the collective model. The simplest manner, and perhaps the most natural one in the absence of price variation, is to assume that the Hicksian good $C$ is collectively consumed - i.e., individual utilities are of the form $U^{i}\left(1-h^{i}, C\right)$. In this context, one can show (Chiappori and Ekeland, 2002 and forthcoming; Donni, forthcoming) that the knowledge of individual labor supply functions generically allows exact identification of the structural model, i.e. preferences and Pareto weights, at least when the number of hours is continuous (the extension to discrete participation, in the 
spirit of the present paper, is left for further research).

In a more general setting, public and private consumptions can be simultaneously considered. Then difficult identification problems arise. While preferences over the private goods can readily be identified conditional on the quantities consumed of the public goods, general identification typically requires additional information or more structure. A natural solution is to assume that private consumption is separable, with member $i$ 's utility of the form $W^{i}\left[u^{i}\left(1-h^{i}, C^{i}\right), K\right]$ (here $K$ denotes public consumption, assumed observable). ${ }^{26}$ Even in the absence of price variation (i.e., assuming that the price of both the public and the private good are normalized to one), this model is generically identifiable in a general, nonparametric sense: the observation of labor supply and demand for public good as (continuous) functions of wages and non labor income allows to uniquely recover the underlying structural model. Specifically, once the demand for public good is known, then one can also recover the utility indices $W^{i}$ and the decision process, as summarized by the corresponding, individual Pareto weights. ${ }^{27}$ This first model can be extended in different ways to include the case where the production of the public good also requires leisure.

Finally, an interesting perspective is provided in a recent contribution by Zhang and Fong (2000). In their model, leisure is partly private and partly public, in the sense that member i's leisure $(i=m, f)$ can be written as $L^{i}=L_{p}^{i}+L$ where

\footnotetext{
${ }^{26}$ Note, however, that given the collective structure of the model, at the household level there will be no separability property between members' leisure and the demand for public good.

${ }^{27}$ In practice, efficiency requires that the household demand and labor supplies solve a Pareto program of the form:

$$
\max \lambda W^{1}+(1-\lambda) W^{2}
$$

under budget constraint. The outcome of the decision process (i.e., the location of the final choice on the Pareto frontier) is fully summarized by the Pareto weight $\lambda$. In addition, if the $W^{i}$ are such that private and public consumptions are normal goods, then there exists an increasing, one-to-one correspondance between the Pareto weight $\lambda$ and the sharing rule $\rho$ (as functions of wages and non labor income).
} 
$L_{p}^{i}$ represents i's private leisure and $L$ is the common leisure of the couple. While individual labor supplies (hence total leisures) are observable, the allocation of time between private and public leisure is not. Under mild separability assumptions, Zhang and Fong show the following result: if there exist a private good (at least), the husband's and the wife's consumptions of which are independently observable, then the structural model (including the allocation of leisure between private and public time) can be fully recovered. Again, this result suggest that data on private consumptions can help achieve identification of more general models, entailing private and public consumptions. As an example of such private consumption, one may think of clothing, as in Browning et al. (1996).

\subsection{The Extension to Household production}

In Blundell, Chiappori, Magnac and Meghir (2000) we discuss the extension to household production. The generalization we consider is the case where the produced good is privately consumed. The framework follows that proposed in Chiappori (1997) in which there are two leisure and two private consumption goods: One market good $c$, the price of which is normalized to one, and a domestic good $x$, that can be produced within the household. In the production function of the domestic good, we allow for differences in marginal productivity of labor between members, which can account for partial specialization (time input being non zero for each member). Also, given that quantities of the $x$ good are not observable, it is natural to assume that the technology exhibits constant returns to scale. A standard issue in household production models is whether there exists a market for good $x .^{28}$ When the domestic good is marketable and when the quantity actually purchased on the market, denoted $x^{M}$, is positive, then in the decision process it

\footnotetext{
${ }^{28}$ For instance, meals can be taken at home or at restaurant; one can either clean one's house or pay a cleaning lady to perform the job; etc..
} 
is valued at its market price which is exogenous for the household. Otherwise, we can still define a shadow price, $\pi$, for the domestic good, that is some endogenous, household-specific function of wages and non labor income.

In this generalized set up, the sharing rule is shown to exist. A generalized version of the double indifference result also holds but identification is still an open issue. However we can show identification in parametric cases where there is no market and where the shadow value is affected by individual preferences. However, identification with household production requires time use data; this is because the model is informative about the woman's leisure rather than her work time. With no household production leisure is simply the complement of hours of work. This is no longer the case with household production where non-market time is shared between leisure and productive activities.

An alternative approach has recently been proposed by Donni (2004), who characterizes the bias arising from a misspecification of the model that omits household production. He first shows that, for a large class of household production technologies, the models with and without home production are empirically undistinguishable, although they may lead to different welfare recommendations. This negative result must however be qualified for two reasons. First, some conclusions obtained in the model without home production (the 'reduced' model) remain valid in the general model; for instance, the consequences of exogenous changes in non labor incomes and distribution factors, a key aspect for policy evaluation, are the same in both contexts, so that a welfare evaluation performed in the reduced model remains valid in general (a conclusion already mentioned in Chiappori 1997). Second and more importantly, this conclusion extends to wage variations as well, provided that the household technology is additively separable; in that case, the reduced model is a valid tool for welfare analysis, in the sense that any policy evaluation 
based on it has general validity. For instance, a model in which men and women perform different tasks, or one in which male supply of household work is inelastic, can be analyzed in our framework without introducing biases.

\section{Summary and Conclusions}

In this paper we have specified a model of family labor supply based on the collective framework. The framework we develop allows identification of preferences without using information on preferences for singles. We have introduced two important theoretical innovations which match the empirical evidence on labour supply: First we allow the possibility that one or both partners do not work. Second we allow for the possibility that one of the partners makes just a discrete work choice, i.e. to work or not. We show that knowledge of the male participation rule and knowledge of the female labor supply schedule, allows us to test the collective restrictions and to recover the individual preferences as well as the rule governing sharing of household resources, as a function of market wages and other incomes.

We use this framework to analyze family labor supply using data from 1978 to 2001. The data is not at odds with the collective model, but the unitary model is rejected. Once we estimate the collective model we find that female wage elasticity is about 0.30 which is very close to the figure that earlier UK studies have found, including work on single parents. Moreover we find that the level of male consumption is sensitive to wages and other income. Although he gets to consume all the increase in his earnings, increases in the female wage and other income lead to substantial increases in her consumption. The implication is that the improvement in the labor market conditions for women over the last two or more decades would have translated to significant improvements in their relative welfare. The paper concludes by considering two possible extensions of the basic 
framework: household public goods and household production, and we argue that in many cases the conclusions of our 'reduced' model still apply.

A number of issues have been raised by our approach, which have been beyond the scope of this paper. These include job-search and life-cycle considerations including the study of retirement. It is particularly interesting to see how the collective model can inform the decisions of a couple to retire when facing dynamic incentives in pensions and Social Security. Even more ambitiously one could include within the model an explicit decision to form a relationship and keep it going. This would also involve dynamic considerations. What we demonstrate here is the richness of the Collective model both as an empirical tool for understanding within family allocations and as a theoretical tool for considering the key issue of how individuals share resources and what this may mean for targeting of policies.

\section{Appendices}

\section{A Proof of Proposition 1}

\section{A.1 Identification on the participation frontier}

On any point on the frontier, (14) is a non-linear system of equations in the unknowns $\left(\Psi_{w_{f}}, \Psi_{w_{m}}, \Psi_{y}, F^{\prime}\right)$. The first three equations characterize the three unknowns $\Psi_{w_{m}}, \Psi_{y}$ and $F^{\prime}$. Specifically, from the first two, one gets that

$$
\begin{aligned}
\Psi_{y} & =\frac{1}{(a-b)}\left(a-1-\frac{b}{F^{\prime}}\right) \\
\Psi_{w_{m}} & =\frac{b}{(a-b)}\left(a-1-\frac{a}{F^{\prime}}\right)
\end{aligned}
$$

where

$$
\begin{aligned}
a & =a\left(w_{f}, y\right)=A\left[w_{f}, \gamma\left(w_{f}, y\right), y\right] \\
b & =b\left(w_{f}, y\right)=B\left[w_{f}, \gamma\left(w_{f}, y\right), y\right]
\end{aligned}
$$


Replacing in the third equation in (14) gives the following equation in $F^{\prime}$ :

$$
\left(\gamma_{y} b a-1+a-\gamma_{y} b\right)\left(F^{\prime}\right)^{2}+\left(-b+1-2 \gamma_{y} b a+\gamma_{y} a-a\right) F^{\prime}+b+\gamma_{y} b a=0
$$

This equation must have a solution, hence the standard discriminant condition:

$$
\left(-2 \gamma_{y} a b+\gamma_{y} a-b-a+1\right)^{2} \geq 4\left(\gamma_{y} a b+b\right)\left(a-1+\gamma_{y} a b-\gamma_{y} b\right)
$$

Conversely, assume this condition is satisfied. Let $\phi\left(w_{f}, y\right)$ be a solution of the quadratic equation above (note that there are at most two such solutions). We know that if this function corresponds to a solution, then it is such that:

$$
F^{\prime}\left[\Psi\left(w_{f}, \gamma\left(w_{f}, y\right), y\right)\right]=\phi\left(w_{f}, y\right)
$$

Then the partials $\Psi_{w_{m}}, \Psi_{w_{f}}$ and $\Psi_{y}$ are identified - although, of course, on the frontier only. Specifically, one can define three functions $K, L$ and $M$ such that:

$$
\begin{aligned}
\Psi_{w_{m}}\left[w_{f}, \gamma\left(w_{f}, y\right), y\right] & =K\left(w_{f}, y\right)=\frac{b}{(a-b)}\left(a-1-\frac{a}{\phi\left(w_{f}, y\right)}\right) \\
\Psi_{w_{f}}\left[w_{f}, \gamma\left(w_{f}, y\right), y\right] & =L\left(w_{f}, y\right)=\frac{\gamma_{w_{f}}}{(a-b) \gamma_{y}}\left(a-1-\frac{b}{\phi\left(w_{f}, y\right)}\right) \\
\Psi_{y}\left[w_{f}, \gamma\left(w_{f}, y\right), y\right] & =M\left(w_{f}, y\right)=\frac{1}{(a-b)}\left(a-1-\frac{b}{\phi\left(w_{f}, y\right)}\right)
\end{aligned}
$$

Now, let us consider the testable restrictions implied by these results. First, that $F^{\prime}$ can be written as a function of $\Psi$ only has a consequence, namely that

$$
\frac{\phi_{w_{f}}}{\phi_{y}}=\frac{\Psi_{w_{f}}+\Psi_{w_{m}} \gamma_{w_{f}}}{\Psi_{y}+\Psi_{w_{m}} \gamma_{y}}=\frac{L+K \gamma_{w_{f}}}{M+K \gamma_{y}}=\frac{\gamma_{w_{f}}}{\gamma_{y}}
$$

which implies that the function $\phi$ can be written as some function of $\gamma$.

Moreover, $\Psi_{w_{m}}, \Psi_{w_{f}}$ and $\Psi_{y}$ are the partials of the same function. This implies the following condition:

$$
L_{y}-M_{w_{f}}=\gamma_{y} K_{w_{f}}-\gamma_{w_{f}} K_{y}
$$


Since the functions $K, L, M$ and $\phi$ are exactly identified from the functions $a, b$ and $\gamma$, these two equations are testable restrictions upon the latter functions. Finally, the quadratic equation defining $\phi$ may have two solutions. But, generically, one (at most) will satisfy the two conditions above. In addition, the function $F$ is identified up to an additive constant.

In summary: the function $\Psi$ and function $F$ are identified up to an additive constant on the male participation frontier.

\section{A.2 Identification outside the frontier}

We now consider the general problem of identifying the sharing rule off the participation frontier. Let us start by the participation set $P$ when the female participates $\left(h_{f}>0\right)$. We will assume that for all $\left(w_{f}, y\right): a\left(w_{f}, y\right) \cdot \gamma_{y}\left(w_{f}, y\right)+1 \neq$ 0. Under this assumption we have:

Lemma 4 On $P, \Psi$ is identified up to an additive constant.

Proof. We know that $\Psi$ must satisfy the partial differential equation (5), i.e.:

$$
-\Psi_{w_{m}}+A \Psi_{y}=A-1
$$

In addition, the values of the partials on the frontier have been identified above. The basic idea, now, is that the latter provide boundary conditions for the partial differential equation. From standard theorems in partial differential equation theory, this defines $\Psi$ (up to an additive constant) provided the following condition is fulfilled. First, remark that, at any point on the frontier, (36) can be written as :

$$
\nabla \Psi \cdot \vec{u}=A-1
$$

where $\nabla \Psi$ denotes the gradient of $\Psi$, and $\vec{u}$ is the vector $(0,-1, A)^{\prime}$. Now, the condition is that $\vec{u}$ is not tangent to the frontier $L$. Since the equation of $L$ is :

$$
w_{m}-\gamma\left(w_{f}, y\right)=0
$$


and given that, on the frontier, $A$ coincides with $a$, this condition states that, for all $\left(w_{f}, y\right)$ :

$$
a\left(w_{f}, y\right) \cdot \gamma_{y}\left(w_{f}, y\right)+1 \neq 0
$$

If this relation is fulfilled on the frontier, then the PDE (5), together with the boundary condition, defines $\Psi$ up to an additive constant.

Practically, there are cases where the PDE can be solved analytically. Then the solution is defined up to a function of 2 variables; and this function is identified by its values upon the frontier. The next section provides an example on a specific functional form. Even when the PDE cannot be solved analytically, it is always possible to numerically compute $\Psi$ using the PDE and the boundary condition on the frontier. See Appendix A for the detail of the algorithm.

In the non-participation set $(N)$, the approach is exactly the same :

Lemma 5 Assume that, for all $\left(w_{f}, y\right)$ :

$$
b\left(w_{f}, y\right) \cdot \gamma_{y}\left(w_{f}, y\right)+1 \neq 0
$$

Then on $N, \Psi$ is identified up to an additive constant.

Proof. As above, using the PDE

$$
-\Psi_{w_{m}}+B \Psi_{y}=\frac{B}{F^{\prime}}
$$

(remember that $F^{\prime}$ has been exactly identified above).

Note, incidentally, that generically both (36) and (38) are fulfilled almost everywhere on the frontier.

For any (arbitrary) value of the constant, the equations (4) and (8) allow to recover the Marshallian demand $H$; then preferences can be identified in the usual way. Finally, note that integration requires at that stage additional restrictions. 
While Slutsky symmetry is not binding with only two goods, the sign of compensated own price elasticity still has to be positive, a constraint that can readily be verified.

To see the intuition underlying the restrictions of the collective model note that they reflect the fact that wages have three effects. Two are the familiar income and substitution effects of price (or wage) changes. The third effect, which is specific to the collective model, is that any wage (or income) variation may affect the sharing rule (say, through its impact on bargaining power). The nature of the collective approach is that this latter effect is not restricted. However, any given change in the sharing rule must impact on a member's labor supply in the same way whatever the origin of the change. This, together with the fact that the sharing rule affects the disposable income of both agents, generates the restrictions implied by the collective setting.

\section{B Unrestricted Estimates}

\section{References}

[1] Apps, P.F. and Rees, R. (1996),'Labor Supply, Household Production and Intra-Family Welfare Distribution", Journal of Public Economics, 60, 199219.

[2] Arellano, M. and Meghir, C. (1992), "Female Labor Supply and On-the-Job Search: An Empirical Model Estimated using Complementary Data Sets", Review of Economic Studies, 59, 537-59.

[3] Attanazio, O., and M. Mazzocco (2001), 'Intra-household Allocation with Limited Commitment: an Empirical Characterization, mimeo, University of Wisconsin-Madison 


\begin{tabular}{|c|c|c|c|c|c|c|}
\hline & \multicolumn{2}{|c|}{ Male Participation } & \multicolumn{4}{|c|}{ Female Labor Supply } \\
\hline & & & \multicolumn{2}{|c|}{ Male Works } & \multicolumn{2}{|c|}{ M. out of Work } \\
\hline Male wage & 0.008 & 0.022 & -0.702 & 0.319 & 1.97 & 1.12 \\
\hline Female log wage & -0.210 & 0.128 & 7.32 & 1.630 & 11.8 & 7.02 \\
\hline unearned income & -0.174 & 0.007 & -1.19 & 0.125 & -1.97 & 0.344 \\
\hline Male Age & -0.010 & 0.005 & -0.061 & 0.058 & 1.00 & 0.294 \\
\hline Female Age & 0.014 & 0.005 & -0.604 & 0.067 & -0.496 & 0.299 \\
\hline Male education & 0.0064 & 0.013 & -0.667 & 0.200 & -1.06 & 0.680 \\
\hline \multicolumn{2}{|l|}{ Sample } & & \multicolumn{2}{|c|}{8008} & \multicolumn{2}{|c|}{1553} \\
\hline \multicolumn{7}{|c|}{$\begin{array}{l}\text { Time dummies included. Standard errors in italics. The Female wage is measured } \\
\text { in } £ \text { per hour other income and male weekly earnings are divided by } 40 \text {. Means: } \\
\text { log wage is } 1.74 \text {, male wage (divided by } 40 \text { ) is } 8.7 \text {, other income (divided by } 40 \text { ) } \\
\text { is -6.5. Male participation for those over } 30 \text { includes cohort dummies. } \\
\text { All equations include a full set of time dummies. The standard errors taking into } \\
\text { account the entire estimation process have been computed using the bootstrap }\end{array}$} \\
\hline
\end{tabular}

Table 2: Unrestricted labour Supply estimates - No Selection correction

[4] Blundell, R. W. and T. MaCurdy, (1999), "Labor Supply : A Review of Alternative Approaches", Handbook of Labor Economics, 3:1560-1695.

[5] Blundell, R. W. and Walker, I. (1986), 'A Life Cycle Consistent Empirical Model of Labor Supply using Cross Section Data', Review of Economic Studies, 53, 539-58.

[6] Blundell, R.W., Duncan, A. and Meghir, C. (1998), 'Estimating Labor Supply Using Tax Policy Reforms', Econometrica, 66(4): 827-61.

[7] Blundell, R. W., P.A. Chiappori, T. Magnac and C. Meghir (2000) "Collective Labor Supply and Household Production", mimeo November

[8] Browning. M., Bourguignon, F., Chiappori, P.-A. and Lechene, V., (1996), 'Incomes and Outcomes: A Structural Model and Some Evidence from French Data', Journal of Political Economy, 102, 1067-96.

[9] Browning M. and P.-A. Chiappori (1998), " Efficient Intra-Household Allocations: a General Characterization and Empirical Tests", Econometrica, 66:1241-78. 
[10] Chiappori, P.-A. (1988), 'Rational Household Labor Supply', Econometrica, $56,63-89$.

[11] Chiappori, P.-A. (1992), 'Collective Labor Supply and Welfare', Journal of Political Economy, 100, 437-67.

[12] Chiappori, P.-A. (1997), "Introducing Household Production in Collective Models of Labor Supply, Journal of Political Economy, 105, 191-209.

[13] Chiappori, P.A., R., Blundell and C., Meghir (2001), "Collective Labor Supply with Children", mimeo.

[14] Chiappori, P.-A. , and I. Ekeland (2002): "The Micro Economics of Group Behavior: Identification', Mimeo, University of Chicago

[15] Chiappori, P.-A. , and I. Ekeland (forthcoming), "The Micro Economics of Group Behavior: General Characterization", Journal of Economic Theory.

[16] Chiappori, P.A., B. Fortin and G. Lacroix (2002), "Marriage Market, Divorce Legislation and Household Labor Supply", Journal of Political Economy, 110(1): 37-72.

[17] Chiappori, P.A., and Donni, O. (2005), 'Learning From a Piece of Pie: The Empirical Content of Nash Bargaining', Mimeo, Columbia University.

[18] Donni, O. (2004), 'Labor Supply, Home Production and Welfare Comparisons', Mimeo, University of Cergy-Pontoise

[19] Donni, O. (2003), 'Collective Household Labor Supply : Nonparticipation and Income Taxation', The Journal of Public Economics, 87, 1179-1198.

[20] Duflo, E (2003), "Grandmothers and Granddaughters: Old Age Pension and Intra-household Allocation in South Africa," World Bank Economic Review $17(1), 1-25$.

[21] Fortin, Bernard and Lacroix, Guy (1997), "A Test of Neoclassical and Collective Models of Household Labor Supply", Economic Journal, 107, 933-955.

[22] Gosling, A, S. Machin and C. Meghir, (2000).'The changing distribution of male wages in the UK', Review of Economic Studies, 67(4):635-666.

[23] Haddad, L., and R. Kanbur (1992), "Intra-Household Inequality and the Theory of Targetting", European Economic Review, 36, 372-78. 
[24] Kapteyn A. and P. Kooreman (1992) "Household Labour Supply: What kind of Data can tell us how many decision makers there are?", European Economic Review, 36:365-71.

[25] Kooreman, P. and Kapteyn, A. (1990), 'On the Implementation of Some Game Theoretic Models of Household Labor Supply', Journal of Human Resources, 25, 584-98.

[26] Ligon, E. (2002), "Dynamic Bargaining in Households", Mimeo, UC Berkeley.

[27] Lundberg, S, (1988),'Labor Supply of Husbands and Wives', Review of Economics and Statistics, 70, 224-35.

[28] MacLeod, B., and J. Malcomson (1993), "Investments, Holdup, and the Form of Market Contracts", American Economic Review, 83, 811-837.

[29] MaCurdy, T. (1983), "A Simple Scheme for Estimating an Intertemporal Model of Labor Supply and Consumption in the Presence of Taxes and Uncertainty", International Economic Review, 24:265-289.

[30] Mazzocco, M., (2003a), "Intertemporal Behavior and Household Structure," Manuscript, Department of Economics, University of Wisconsin.

[31] Mazzocco, M., (2003b), "Household Intertemporal Behavior: a Collective Characterization and a Test of Commitment," Manuscript, Department of Economics, University of Wisconsin.

[32] Mazzocco, M., (2004), "Savings, Risk Sharing and Preferences for Risk," American Economic Review, Vol. 94,No. 4, 1169-1182.

[33] Meghir, C. and E. Whitehouse (1997) "Labour Market Transitions and Retirement in the UK", Journal of Econometrics

[34] Neary, J.P. and Roberts, K.W.S. (1980),'The Theory of Household Behaviour under Rationing' European Economic Review, 13, 24-35.

[35] Thomas, D. (1990),'Intra-household Resource Allocation: An Inferential Approach', Journal of Human Resources, 25, 635-664.

[36] Udry, C. (1996), " Gender, Agricultural Production, and the Theory of Household", Journal of Political Economy, 1010-1046.

[37] Zhang, J., and K. Fong (2001), 'The Identification of Unobservable Independent and Spousal Leisure', Journal of Political Economy, 109(1), 191-202. 